PACS 66.10.-x,Cb; 68.45.-v, 82.65.Yh

\title{
STUDIES ON NONEQUILIBRIUM PHYSICO-CHEMICAL PROCESSES IN THE SYSTEM "FUEL CONTAINING MASSES - AQUEOUS SOLUTIONS OF RADIOACTIVE ELEMENTS"
}

\author{
I.R.YUKHNOVSKII ${ }^{(1)}$, M.V.TOKARCHUK ${ }^{(1)}$,

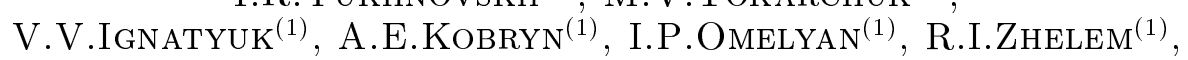 \\ G.S.DMYTRIV $^{(2)}$, O.L.IVANKIV ${ }^{(1)}$ \\ (1) Institute for Condensed Matter Physics \\ of the National Academy of Sciences of Ukraine \\ 1 Svientsitskii St., UA-290011 Lviv-11, Ukraine \\ ${ }^{(2)}$ Inorganic Chemistry Department, Lviv State University \\ $8^{a}$ Kyryl and Mefodij St., UA-290005 Lviv-05, Ukraine
}

Received December 19, 1997

\begin{abstract}
The main forms of nuclear fuel remaining inside the "Shelter" object and the main interrelated factors of nuclear and ecological danger are considered. Processes of interaction of fuel containing masses with water are analysed on the basis of experimental data. A statistical model for the description of radioactive elements is proposed. The pair structure distribution functions for ions $\mathrm{UO}_{2}^{2+}, \mathrm{Cs}^{+}$and $\mathrm{Sr}^{2+}$ in aqueous solutions use this model. Chemical reactions of complex formations with the participation of $\mathrm{UO}_{2}^{2+}$ and $\mathrm{PuO}_{2}^{2+}$ as well as reactions of radiolysis in aqueous solutions of radioactive elements are analysed. Nonuniform equations for the description of $\mathrm{UO}_{2}^{2+}, \mathrm{Cs}^{+}$and $\mathrm{Sr}^{2+}$ ions diffusion from glassy-like fuel containing masses into water and equations of chemical kinetics of radiolysis processes are obtained as well. The shear viscosity and mutual diffusion coefficients of ions $\mathrm{UO}_{2}^{2+}$, $\mathrm{PuO}_{2}^{2+}, \mathrm{Cs}^{+}$and $\mathrm{Sr}^{2+}$ in aqueous solutions are calculated numerically for concentrations which are typical of the "Shelter" object.
\end{abstract}

\section{Introduction}

The investigation of ecological problems of the Chornobyl zone was renewed in 1994 and aimed at active elements migration in soils, ground water near the places of temporary location of active wastes (PTLAW). The main problem was to investigate physical and mathematical models of active elements migration in PTLAW taking into account ion exchange, hydration, mutual diffusion mechanisms of interaction with water and ground corrosion including porous, acidic and adsorption properties. The model, coupled with GIS technologies for PTLAW, was expected to predict PTLAW active elements migration and enable one to work out practical ways of solving these problems.

The subject of early studies was unique water solutions containing uranium (the whole isotopic content), plutonium, americium, curium, cesium, strontium and others. One cannot create them in laboratory conditions. (C) I.R.Yukhnovskii, M.V.Tokarchuk, V.V.Ignatyuk, A.E.Kobryn, I.P.Omelyan, R.I.Zhelem, G.S.Dmytriv, O.L.Ivankiv, 1997

ISSN 0452-9910. Condensed Matter Physics 1997 No 12 (63-96) 
The theoretical description of physical and chemical processes in these specific objects has not been done yet. Besides, a great interest arises as to aqueous solutions of this kind in view of unpredictable consequences of water interaction with fuel containing masses (FCM) inside the "Shelter" object.

We have made a review $[1,2]$ of the published data on the state of FCM- nuclear magma in the "Shelter" object and considered the main interaction processes of FCM with water. The conclusion is as follows: water by means of complex physical and chemical impacts destroys glassy FCM that results in an uncontrolled outflow of uranium, plutonium, cesium, strontium from the lakes at the "Shelter" object.

First of all, a survey of archive materials, reports of the Interbranch Scientific and Technical Center (ISTC) "Shelter" of the National Academy of Sciences of Ukraine concerning FCM state, their chemical composition, $\alpha, \beta$ and $\gamma$-radiation, neutron sources and currents, as well as water availability in the "Shelter" object has been done. Generalizations and a sophisticated analysis of the published materials, archive documents and reports [3-25] have led us to the conclusion that the nuclear, physical and chemical state of fuel in the destroyed nuclear reactor of the 4th power block has remained the main problem at the Chornobyl nuclear power plant during 11 years. The first and the most important question is the amount of nuclear fuel which was in the destroyed reactor immediately after the accident. There is no clear answer to it so far. The second important question is related to the FCM-water interaction inside the "Shelter" object. These questions arise in almost all the conclusions of "Technical substantiation of the nuclear safety of the "Shelter" object" [3]. Investigation on the results of such an interaction and the corresponding processes which are expected in the near future will be the line of further activity of the scientific group at the Institute of Condensed Matter Physics (ICMP) of the National Academy of Sciences of Ukraine.

Kinds of the nuclear fuel and connected with it factors of nuclear and ecological safety of the "Shelter" object were ascertained [26,27].

By April 26, 1986 nuclear fuel with the uranium content 231.5 tons had been distributed in the 4 -th unit of the Chornobyl nuclear power plant while the reactor mine contained 190.3 tons $\left(215\right.$ tons of $\left.\mathrm{UO}_{2}\right)$.

There was almost 700 kilograms of plutonium in the reactor core $\left({ }^{239} \mathrm{Pu}\right.$ $\sim 420 \mathrm{~kg},{ }^{240} \mathrm{Pu} \sim 175 \mathrm{~kg},{ }^{241} \mathrm{Pu} \sim 50 \mathrm{~kg},{ }^{242} \mathrm{Pu} \sim 15 \mathrm{~kg}$ ). In accordance with official MAGATE reports [4-8], the "Shelter" object contains $\sim 96 \%$ of nuclear fuel. 11-year research conducted by the Complex Expedition from the Kurchatov Institute of Atomic Energy of the Russian Academy of Sciences and after 1992 by the ISTC "Shelter" has led to the conclusion that the nuclear reactor mine is, in fact, empty. Nuclear fuel of various kinds is in the central hall (core fragments), in rooms of the steam distributive corridor, underequipment apartments $(304 / 2,305 / 2)$, in the bubbling pond (ground and first floors). Lava-like masses containing fuel will be called nuclear magma.

Calorimetric measurements show that the nuclear magma contains $135 \pm$ 30 tons of $\mathrm{UO}_{2}$ [8-10], in 1994 additional measurements showed $70 \div 90$ tons $[11,12]$. Direct measurements $[13,16]$ found $23.8 \pm 4.5$ tons of $\mathrm{UO}_{2}$. Thus, summarizing the data in [8-12], [13-16] and estimating the nuclear fuel amount in the central hall from 15 to 40 tons, we can see that more than 100 tons of nuclear fuel have been out of control for 11 years. Even allowing for the accuracy correction of the both measurement procedures, the problem remains unsolved.

At present there are the following main kinds of nuclear fuel remaining 
in the "Shelter" object after the accident at the Chornobyl nuclear power plant:

- uranium dioxide $\mathrm{UO}_{2}$ inside the fuel elements and their fragments - the most dangerous kind, presumably located in the central hall (thousands Röntgens per hour). It has not been investigated practically for 11 years because of the complicated radiative situation and technical state. The mathematical modelling $[17,18]$ of an interaction between core fragments and water for a certain volume in the central hall displayed that an effective neutron multiplication factor was able to exceed unity that is a supercritical state;

- nuclear dust - hot nuclear particles, nearly 15 tons of uranium content [10];

- lava-like nuclear magma - formation that arose after cooling the molten mixture of nuclear fuel and filling materials (dolomite, lead, sand, clay, combinations with boron, etc.): [8,9,12-15]

- brown ceramics - brown glass-like mass with the average density from 1.6 to $3.15 \mathrm{~g} / \mathrm{cm}^{3}$ and $10 \pm 2 \%$ nuclear fuel content having burn-up fraction $12.6 \pm 0.4$ (MW day/kg of U);

- black ceramics - black glass-like mass with the average density from $2.0 \pm 0.2$ to $2.9 \mathrm{~g} / \mathrm{cm}^{3}$ and $5 \pm 1 \%$ nuclear fuel content having burn-up fraction $12.5 \pm 0.5$ (MW day $/ \mathrm{kg}$ of $\mathrm{U}$ );

- slag and slag-like granular nuclear magma;

- pemza-like nuclear magma with the average density $0.14 \div 0.18$ $\mathrm{g} / \mathrm{cm}^{3}$ - produced by an interaction between the molten nuclear fuel and water. The data generalization of radiological properties of radionuclides and characteristics of various nuclear magma samples taking into account the information on the percent content of isotopes ${ }^{234} \mathrm{U},{ }^{235} \mathrm{U},{ }^{236} \mathrm{U},{ }^{238} \mathrm{U}$ is given in $[10,11,27]$.

- aqueous solutions of uranium salts formed as a result of the interaction of nuclear magma with natural and technical water. About $2000 \mathrm{~m}^{3}$ is located in the machine hall, but only about $1000 \mathrm{~m}^{3}$ is under control. There are near $3000 \mathrm{~m}^{3}$ of water inside the premises of the "Shelter" object. The content of boron and gadolinium salts as neutron absorbers is not under control in the reservoirs. In 1994 the upper limit of enriched uranium masses in the water of the lower apartments of the "Shelter" object reached several kilograms [10].

The generalized data on the radionuclide content in the water within the "Shelter" object are presented in many archive materials and reports [10,26-28].

- new mineral uranium combinations on the nuclear magma surface are:

- $\mathrm{UO}_{3} \cdot 2 \mathrm{H}_{2} \mathrm{O}$ - epiyantynite;

- $\mathrm{UO}_{2} \mathrm{CO}_{3}$ - retzerfordine;

- $\mathrm{UO}_{4} \cdot 4 \mathrm{H}_{2} \mathrm{O}$ - studtite;

- $\mathrm{Na}_{4} \mathrm{UO}_{2}\left(\mathrm{CO}_{3}\right)_{3}, \mathrm{UO}_{2}$ part is up to $55 \%$.

These minerals are well soluble in water;

The report of the Kurchatov Institute of Atomic Energy of the Russian Academy of Sciences [24] incorporates tests for the content of isotopes ${ }^{234} \mathrm{U},{ }^{235} \mathrm{U},{ }^{236} \mathrm{U}$ in new yellow and yellow-brown formations [19] on the nuclear magma surface in apartment 210/6. 
A relatively high content of ${ }^{234} \mathrm{U}$ is revealed, furthermore ${ }^{235} \mathrm{U}$ is 1.6 times as large as a normal ratio of ${ }^{235} \mathrm{U} /{ }^{238} \mathrm{U}$ for RBMK- 1000 . Therefore, a conclusion may be drawn that because of complicated physical and chemical processes with the participation of water, uranium is concentrated in these formations. Since new combinations are well soluble in water, we have an active way of uranium outflow from nuclear magma into the "Shelter" reservoirs in a concentrated state;

- chemical deposits containing uranium, plutonium, curium, americium, strontium and cesium in aqueous solutions in the "Shelter" object.

In general, there are such dangerous nuclear fission materials in the "Shelter" object: $\mathrm{UO}_{2}, \mathrm{UO}_{2} \mathrm{UO}_{3}, \mathrm{UO}_{2} \mathrm{CO}_{3}, \mathrm{PuO}_{2},(\mathrm{ZrU}) \mathrm{O}_{x},(\mathrm{ZrU}) \mathrm{SiO}_{4}$, $\mathrm{UO}_{3} \cdot 2 \mathrm{H}_{2} \mathrm{O}, \mathrm{UO}_{4} \cdot 4 \mathrm{H}_{2} \mathrm{O}, \mathrm{Na}_{4} \mathrm{UO}_{2}\left(\mathrm{CO}_{3}\right)_{3}$ with a large amount of neutron moderators $\mathrm{SiO}_{2}, \quad \mathrm{Al}_{2}\left(\mathrm{Si}_{2} \mathrm{O}_{3}\right)(\mathrm{OH})_{4}, \mathrm{Na}_{3} \mathrm{PO}_{4}, \quad \mathrm{C}_{x} \mathrm{H}_{y} \mathrm{O}_{z}, \quad \mathrm{CaMg}\left(\mathrm{CO}_{3}\right)_{2}$, $\mathrm{CaCO}_{3}, \mathrm{~K}_{2} \mathrm{O}, \mathrm{CaO}, \mathrm{MgO}, \mathrm{Fe}_{2} \mathrm{O}_{3}, \mathrm{ZnO}_{2}, \mathrm{H}_{2} \mathrm{O}$, C.

The mentioned above kinds of nuclear fuel in the "Shelter" object ensure its nuclear and ecological safety to a great extent. For this reason, the basic factors of nuclear and ecological danger at the "Shelter" object are:

- nuclear transformations in the core fragments of lavas at the interaction with water (the central hall was not investigated). The contribution of $(\alpha, n)[20,21]$ reactions is important because they generate almost $50 \%$ of neutrons in the nuclear magma, $\beta$-transition of ${ }^{241} \mathrm{Pu}$ into ${ }^{241} \mathrm{Am}$ is an intensive $\alpha$-particle source [20,21,29,30];

- the lava-like solid amorphous state of the nuclear magma transforms into nuclear dust with a gradually decreasing particle size converting into a fine grained fraction $[2,10]$;

- the probability of nuclear dust ejections increases as a result of the disruption under the continuing interior construction-borne radioactivity at the "Shelter" object;

- the mobility of the nuclear fuel fine grained fractions grows essentially due to the interaction with water penetrating inside the "Shelter" object through holes, cracks in the roof, walls and its condensation from the air onto internal walls of the "Shelter" object;

- the interaction between water and lava-like amorphous medium leads to a gradual leaching of radioactive elements which form hydrated complexes in aqueous solutions and may display colloid and polimeric properties $[2,31,32]$;

- the interaction of nuclear magma with water under $\alpha$-, $\beta$-decays and $\gamma$-radiation results in water radiolysis. Products of the water decomposition $\left(\mathrm{H}_{2} \mathrm{O}_{2}\right)$, radicals $\left(\mathrm{OH}, \mathrm{HO}_{2}\right)$ take an active part in the uranium dioxide hydration, while atomic hydrogen $\mathrm{H}, \mathrm{OH}$ groups affect the magma fragility and disintegration [2, 30-32]. The interplay of these processes brings about a rapid increase of the uranium concentration in water: $1991-4900(\mu \mathrm{g}$ of $\mathrm{U}) / \mathrm{l}, 1992-23000(\mu \mathrm{g}$ of $\mathrm{U}) / \mathrm{l}$, $1993-14000(\mu \mathrm{g}$ of $\mathrm{U}) / \mathrm{l}, 1994-18000(\mu \mathrm{g}$ of $\mathrm{U}) / \mathrm{l}, 1995-14000(\mu \mathrm{g}$ of $\mathrm{U}) / \mathrm{l}$;

- if the nuclear fuel in the lava-like amorphous medium is in a subcritical state, its accumulation in water inside the "Shelter" object due to an interaction with water may result in the formation of polymeric structures and increasing the active elements concentration after the 
swelling of these structures and sedimentation together with all the fragments of the fuel core. Then the probability of appearing a supercritical mass and a local self-supported chain reaction increases;

- radioactive elements can penetrate from the "block" water region into the ground waters and travel outside the "Shelter" object. Analysis of the water from the boreholes of the industrial part of the "Shelter" object reveals that the concentration of strontium and cesium increases;

- tritium oxide in the reservoirs of the "Shelter" object.

So, the water factor in the "Shelter" object affects its safety essentially if the filling materials in the destroyed reactor have promoted an intensive decomposition of fuel particles and damping nuclear fission reactions. The nuclear magma pulverization and its interaction with water proceed in the opposite direction and may cause a nuclear fuel concentrating.

An essential trouble is caused by the state of core fragments, their isolated elements and conglomeration being observed after the accident near the broken 4 -th unit. The core fragments were thrown out by the explosion onto the ventilation tube areas, the roof of the 3-rd unit machine hall, however, an evidently greater part remains in the central hall. When managing with the accident consequences, the core fragments were thrown into the central hall from the roof of the object as well.

In the above context one has to pay a particular attention to the results of the reports of $[17,18]$. In [17] there are numerical calculations of the effective neutron multiplication factor for the system modelling conglomerations of reactor's active core fragments in various apartments of the "Shelter" object. The calculations have shown that $\mathrm{K}_{\text {ef }}$ reaches the value of 0.61 for fragment conglomerations in drum separators with the consideration of structural heterogeneity, the value of 0.88 on the scheme " $E$ " and 0.97 for conglemerations in the central hall. In [25], displacements of the building construction elements of the "Shelter" able to vary the geometry of FCM are analysed. Those are shown to be most dangerous that can form nuclear magma of a spherical form. The ruin of the scheme "E" and fall on conglomerations of active core fragments in the central hall and their unification with the nuclear magma in apartment 305/2 were observed. In the case of flood with $0.2 \mathrm{~m}$ deep water [17] the situation can originate a self-sustaining nuclear chain reaction. Computer simulations [17] point out that the water flood of nuclear magma and active core fragments with the increasing percent content of $\mathrm{UO}_{2}$ brings about a rise in the nutron multiplication factor $K_{\text {ef }}$ up to 1.05 that is a supercritical state again.

Similar studies have been recently done in paper [33]. The authors have drawn conclusions about a deep subcriticality for FCM in apartments 304/3 and $305 / 2$ even in the case of water flood. However, this investigation, as well as the previous ones, treat both apartments on the basis of a onedimensional model to be far from real values of multiplication factors and neutron fluxes. One can get a more realistic picture with the help of a threedimensional model taking into consideration fuel heterogeneity, physical and chemical processes which do occur in the system "FCM-water".

Summarizing all that, one can affirm that the irreversible process allowing the nuclear fuel outflow from the nuclear magma into the indoor reservoirs is in progress at the "Shelter" object. It is one of the factors of the object nuclear danger. Therefore, the problem of the water interaction with the active core fragments, nuclear magma, lavas and nuclear dust becomes very acute, since: 
- water interaction with nuclear magma can essentially increase effective neutron multiplication factor $\mathrm{K}_{\mathrm{ef}}[10,18,25]$ and possibly result in local self-sustaining nuclear chain reactions (SNCR);

- water destroys nuclear magma lava by means of radiolysis and complex leaching processes, enabling uncontrolled active elements transport indoors and outdoors of the object.

Hence, the main kinds of nuclear fuel and the basic factors of nuclear and ecological danger of the "Shelter" caused by it are primarily connected with the availability of water. The water factor discussed during the last four years, shifted the accents of the Technical substantiation of nuclear safety (TSNS - 1990 [3]) of the "Shelter" object entirely. Moreover, it was shown in [3] that the object is nuclear-dangerous with the presence of 300 g. of ${ }^{235} \mathrm{U}, \mathrm{Ru}$ or their mixture.

The interaction of water with active core fragments (fuel elements, tablets of uranium dioxide), lava-like FCM and nuclear dust should be considered when predicting disruption phenomena and calculating probability of local SNCRs in the system "active core fragments - FCM - water". According to the latest studies, water is an intensive destroyer of FCM, but at the same time it is an effective neutron moderator. Special features of transuranic elements aqueous solutions are caused to a great extent by hydrolysis, complex formation and also variety of oxidation degrees. The formation of polynuclear structures under these conditions is to be investigated.

For a detailed understanding of the FCM destruction, uranium yield in water and prognostication of these processes, we have carried out an investigation $[31,33]$ of the structural distribution and diffusion processes of ions $\mathrm{UO}_{2}^{2+}, \mathrm{Sr}^{2}+, \mathrm{Cs}^{+}$in the system "glassy-like $\mathrm{FCM}$ - water". Chemical reactions between aqueous solutions of radioactive elements and glassy FCM have been analysed, the main mechanisms of surface destruction (hydrogen, water molecules, $\mathrm{OH}$ group influence) and the leaching of $\mathrm{UO}_{2}^{2+}$, $\mathrm{Sr}^{2}+, \mathrm{Cs}^{+}$ions from the glassy matrix have been established. Radiolysis processes [30,31] in alkali aqueous solutions of radioactive elements are considered, the role of hydrogen ions, hydrated electrons and $\mathrm{OH}$ groups is established. Chemical reactions for the creation of minerals $\mathrm{UO}_{2} \mathrm{CO}_{3}, \mathrm{UO}_{4}$. $4 \mathrm{H}_{2} \mathrm{O}, \mathrm{Na}_{4} \mathrm{UO}_{2}\left(\mathrm{CO}_{3}\right)_{3}$ in the system "glassy $\mathrm{FCM}$ - water" are analysed.

At present the calculations of diffusion, thermal conductivity and viscosity coefficients for ions $\mathrm{UO}_{2}^{2+}, \mathrm{Sr}^{2+}, \mathrm{Cr}^{+}$in glassy $\mathrm{FCM}$ and water solutions of active elements are in progress.

The nonequilibrium transport of particles and energy in lava-like fuel containing materials inside the "Shelter" to a great extent determine their stability and disruption processes. In doing so, the description of ionic or neutral uranium, plutonium, americium and curium in nuclear magma is very important. First of all, it is connected with the fact that the main sources of $\alpha$-activity and spontaneous fission neutrons are the isotopes ${ }^{238-240} \mathrm{Pu},{ }^{241} \mathrm{Am},{ }^{242} \mathrm{Am}$ (spontaneous fission), ${ }^{242} \mathrm{Cm},{ }^{244} \mathrm{Cm}$ providing $99 \%$ and $96 \%$ of $\alpha$-activity and neutron outflow from 5 to 10 years after the accident. The interaction of the emitted $\alpha$-particles with the atoms of $\mathrm{B}, \mathrm{O}$, $\mathrm{Na}, \mathrm{Mg}, \mathrm{Al}$ and $\mathrm{Si}$ in the nuclear magma is accompanied by the reaction $(\alpha$, n) generating a supplementary neutron flux. Estimations of $(\alpha, n)$ reactions for some magma samples from under-reactor apartments 305/2 and 304/3 reveal that their contribution to the neutron generation rate in the nuclear magma reaches $\approx 50 \%$. 
It should be noted that the neutron generation rate will increase with time flow due to $(\alpha, n)$ reactions on light elements. It is caused, first of all, by the accumulation of americium ${ }^{241} \mathrm{Am}$ (after $\beta$-decay of ${ }^{241} \mathrm{Pu}$ ) as an intensive $\alpha$-particle source.

One has to point out that americium ${ }^{241} \mathrm{Am}$, among similar to it isotopes, has a large thermal-neutron fission cross-section, namely 3.13 barns. For the consideration of actinides in the nuclear magma, the curves for fission fragments of ${ }^{241} \mathrm{Pu},{ }^{241} \mathrm{Am}$ by slow neutrons may be useful. Neutron fields in the nuclear magma in apartments 305/2, 304/3 were studied. In particular, a significant divergence between experimental and numerical data was observed at the investigation of fission densities, cadmium ratios and spectral indices for the nuclear magma in apartment 304/3. Especially great difference in the magnitude is found for the neutron flux density (the experimental values are almost 20 times as large as the numerical ones). Evidently, it can be explained by the fact that the computational models do not take into account the peculiarities of the content, structure, neutron source strength and radionuclide transport in the nuclear magma. Recent investigations dealt with the estimation of the neutron current for the FCM models in the central hall, which contact with water. But the contribution of $(\alpha, n)$ reactions, that can amount $50 \%$, has not been considered in the calculations.

In connection with the above mentioned problems, we have obtained $[29,30]$ a system of equations for neutron transfer kinetics taking into consideration the transport processes of particles in FCM. This is one of the versions for the investigation of neutron diffusion and nuclear processes using a three-dimentional model of FCM.

The transport of radionuclides by the ground soil and underground waters in the system the "pumping of the nearby zone of the Chornobyl nuclear power plant - the Prypjat' river - the cascade of the Dnieper storage lakes" and the processes occurring in the burial grounds of PTLAW in the $30-\mathrm{km}$ Chornobyl zone are the main problems concerning the consequences of the accident at the Chornobyl plant. The PTLAW (burial places of parts of buildings, radioactive grounds, forests, parts of metallic constructions, etc.) were created in the conditions of a highly radioactive background in a very short period of time without a proper technical execution (the absence of hydroisolated layers) during the desactivation of the territory around the Chornobyl plant. The PTLAW near the "Yaniv" station and the point "Oil Storehouse" [34,35] (investigations for the content of ${ }^{137} \mathrm{Cs}$ and ${ }^{239} \mathrm{Pu}$ in the ground waters at their migration from trenches), which are flooded by water, attract special attention. The "red" wood [36,37] has been creating conditions for an uncontrolled penetration of radionuclides, such as Cs, $\mathrm{Sr}, \mathrm{Pu}$ and $\mathrm{Am}$, into the environment. In particular, in [37] the problem of americium and plutonium in the ground waters of the "red" wood was emphasized.

Another possible source of radionuclides in the ground waters is the "Shelter" object. In the bore holes on its industrial territory one can observe an increase in the concentration of $\mathrm{Sr}$ and $\mathrm{Cs}$. It can be connected with the penetration of the "block" water into the ground outside the object [38] or with the interaction of the surrounding wet grounds with the dry radioactive grounds of the "Shelter" object. The diffusion processes in this case are determined not only by concentration gradients, but also by electrostatic effects which have not been taken into account up to now. In our papers $[1,30]$, osmotic processes of the radionuclide transport in the ground waters were discussed.

In this paper we present some results of the investigation of physico- 
chemical processes (diffusion, radiolysis, chemical reactions) in the system "glassy FCM (nuclear magma) - aqueous solutions of radioactive elements (water)".

\section{Nonequilibrium physico-chemical processes in the system "glassy fuel containing masses - aqueous solutions"}

\section{1. $\quad$ Statistical Model}

We are going to treat an interaction of nuclear magma with water by means of a model two-phase system "nuclear magma-water". The nuclear magma was formed as a result of high temperature melting and gradual solidification of the nuclear fuel along with boron, dolomite, lead, sand, clay combinations which were thrown into the reactor to decrease the temperature and terminate active nuclear processes. The global problem of nuclear fuel decomposition was solved. It resulted in a glassy inhomogeneous solid medium in the form of avalanches containing a number of highly active nuclides: $U$, $\mathrm{Pu}, \mathrm{Cs}, \mathrm{Ce}, \mathrm{Am}, \mathrm{Cm}, \mathrm{Zr}, \mathrm{Sb}$ and their isotopes. Reasoning from the chemical content of the samples $[11,12,19,39]$, nuclear magma is argued to be multicomponent glass $[40,41]$ in a structure with the inherent ionic bond -O-Si-O-, -Ca-O-, -O-Al-O-, and belong to sital-like glass: $\mathrm{CaO}-\mathrm{MgO}-\mathrm{FeO}-$ $\mathrm{Fe}_{2} \mathrm{O}_{3}-\mathrm{Al}_{2} \mathrm{O}_{3}-\mathrm{SiO}_{2}$.

Thus, nuclear magma has a silicate matrix filled with impurities which are different in the chemical content [11] including up to $18 \% \mathrm{UO}_{2}$ uranium oxide. Mainly, ionic bonds are available between the impurities and the silicate matrix, thus, those impurities might be regarded as ionic clusters (e.g. uranyl ion $\mathrm{UO}_{2}^{2+}$ ) inside the silicate matrix. In connection with this the nuclear magma can be represented as a system of interacting ionic clusters with polyvalent radicals $\left(\mathrm{SiO}_{3}\right)_{n}^{2 n-}$ creating a polymeric glass structure.

In view of the aforesaid, we can consider the system "nuclear magmawater" as a statistical model of interaction between ionic clusters and a water solution. It is clear that advancing the model, one should require it to describe the physical and chemical processes occurring in the "Shelter" object in the most realistic manner.

What basic processes need to be treated when investigating nuclear, physical and chemical transformations in the system "nuclear magma-water"? The category of necessary questions includes the following:

1. Diffusion of ionic clusters incorporating active elements or isolated ions in the silicate matrix taking account of coulombic, dipole and resonant kinds of interaction;

2. Diffusion of active elements ions from the nuclear magma surface to water. The investigation of an interaction between water and nuclear magma, taking into consideration both radiolysis, because of $\alpha-, \beta$ decays, $\gamma$-radiation, and chemical reactions.

The diffusion of active elements (in an ionic form) from the nuclear magma surface to water is affected by both the transport of ions or ionic clusters in the very matrices and water radiolysis with chemical reactions occurring in it. It is apparent that the basic processes leading to the diffusion from the silicate matrix to water take place, first of all, in the near-surface layer of the system "nuclear magma - water". The water radiolysis has a specific effect on them, in particular, on the products of radiolysis: ions, radicals and molecular products: $\mathrm{H}_{2} \mathrm{O} \rightarrow \mathrm{e}_{\mathrm{aq}}^{-}, \mathrm{H}_{\mathrm{aq}}^{+}, \mathrm{OH}_{\mathrm{aq}}^{-}, \mathrm{OH}, \mathrm{H}, \mathrm{HO}_{2}, \mathrm{H}_{2}$, 
$\mathrm{H}_{2} \mathrm{O}_{2}$; the index "aq" stands for hydrated ions. To a great extent the above radiolysis products destroy the silicate matrix, increasing the probability of active elements outflow from it into water in an ionic form.

The experimental investigations of the object's aqueous solutions of radioactive elements, with the average concentration of uranium $10 \mathrm{mg} / \mathrm{l}$ and more, show that their pHs are usually in the intervals of $6.5 \div 7$ and $9 \div 10$. The most interesting are solutions in those places of interaction of the nuclear magma with water, where we observe a substantial yield of uranium in water and a high level of the $\alpha$-, $\beta$ - and $\gamma$-radiation of water. High values of $\mathrm{pH}$ are pointing to a certain shift of equilibrium (due to chemical reactions) between groups $\mathrm{OH}^{-}$and $\mathrm{H}^{+}$, and the fact that ions of hydrogen, which are formed in the process of radiolysis, hydratation and other characteristic reactions, quickly react transforming into molecular hydrogen and molecules of water. Besides, atomic hydrogen can be formed in reduction reactions. This value of $\mathrm{pH}$ corresponds to the basic solutions where the concentration of $\mathrm{OH}^{-}$groups is dominant and there is a deficite of hydrogen ions $\mathrm{H}^{+}$. From this point of view it is necessary to analyze chemical reactions with $\mathrm{UO}_{2}^{2+}, \mathrm{PuO}_{2}^{2+}, \mathrm{AmO}_{2}^{2+}$ in the system "nuclear magma - basic solution" taking into account radiolysis and alkalization processes.

In aqueous solutions U, $\mathrm{Pu}$ and its isotopes, strontium $\mathrm{Sr}$, cesium Cs and other radioactive elements produce different forms of hydrated ions, molecules, double and mixed complexes, mono- and polynuclear products of hydrolysis and colloid particles $[42,43]$. Let us analyze a set of reactions where uranium is involved. The approximated schematic set of reactions can be seen as follows. In aqueous solutions uranium has $+3,+4,+5$, +6 states of oxidation. The stability of valency states of uranium in a solution is characterized by the sequence $\mathrm{U}(6) \geqslant \mathrm{U}(4) \geqslant \mathrm{U}(3) \geqslant \mathrm{U}(5)[43]$. The stabilization of the large positive charge of uranium $U(6)$ takes place because in aqueous solutions uranyl ion $\mathrm{UO}_{2}^{2+}$ is produced [44]. The hydrolysis of uranyl ions is governed by the reactions $[43,45]$ :

$$
\begin{aligned}
\mathrm{UO}_{2}^{2+}+\mathrm{H}_{2} \mathrm{O} & \leftrightarrows \mathrm{UO}_{2}(\mathrm{OH})^{+}+\mathrm{H}^{+} \\
\mathrm{UO}_{2}(\mathrm{OH})^{+}+\mathrm{H}_{2} \mathrm{O} & \leftrightarrows \mathrm{UO}_{2}(\mathrm{OH})_{2}+\mathrm{H}^{+} \\
2 \mathrm{UO}_{2}^{2+}+\mathrm{H}_{2} \mathrm{O} & \leftrightarrows \mathrm{U}_{2} \mathrm{O}_{5}^{2+}+2 \mathrm{H}^{+} \\
\mathrm{U}_{2} \mathrm{O}_{5}^{2+}+\mathrm{UO}_{2}^{2+}+\mathrm{H}_{2} \mathrm{O} & \leftrightarrows \mathrm{U}_{3} \mathrm{O}_{8}^{2+}+2 \mathrm{H}^{+} \\
\mathrm{U}_{3} \mathrm{O}_{8}^{2+}+\mathrm{H}_{2} \mathrm{O} & \leftrightarrows \mathrm{U}_{3} \mathrm{O}_{8} \mathrm{OH}+\mathrm{H}^{+} \\
\mathrm{U}_{3} \mathrm{O}_{8} \mathrm{OH}+\mathrm{H}_{2} \mathrm{O} & \leftrightarrows \mathrm{U}_{3} \mathrm{O}_{8}(\mathrm{OH})_{2}+\mathrm{H}^{+} \\
\mathrm{U}_{3} \mathrm{O}_{8}(\mathrm{OH})_{2}+\mathrm{H}_{2} \mathrm{O} & \leftrightarrows \mathrm{U}_{3} \mathrm{O}_{8}(\mathrm{OH})_{3}^{-}+\mathrm{H}^{+} \\
\mathrm{U}_{3} \mathrm{O}_{8}(\mathrm{OH})_{3}^{-}+\mathrm{H}_{2} \mathrm{O} & \leftrightarrows \mathrm{U}_{3} \mathrm{O}_{8}(\mathrm{OH})_{4}^{2-}+\mathrm{H}^{+} \\
\mathrm{U}_{3} \mathrm{O}_{8}(\mathrm{OH})_{4}^{2-}+\mathrm{H}_{2} \mathrm{O} & \leftrightarrows \mathrm{U}_{3} \mathrm{O}_{8}(\mathrm{OH})_{5}^{3-}+\mathrm{H}^{+}
\end{aligned}
$$

The hydrolysis of uranyl $\mathrm{UO}_{2}^{2+}$ can be explained in terms of the formation of monomer $\mathrm{UO}_{2}(\mathrm{OH})^{+}$by the reaction $[45,46]$

$$
\mathrm{UO}_{2}^{2+}+\mathrm{H}_{2} \mathrm{O} \leftrightarrows \mathrm{UO}_{2}(\mathrm{OH})^{+}+\mathrm{H}^{+}
$$

and dimer $\mathrm{UO}_{3} \mathrm{UO}_{2}^{2+}$ by the reaction

$$
2 \mathrm{UO}_{2}^{2+}+\mathrm{H}_{2} \mathrm{O} \leftrightarrows \mathrm{UO}_{3} \mathrm{UO}_{2}^{2+}+2 \mathrm{H}^{+}
$$

A lot of other possible reaction channels can fit into this scheme, thus constituting a complicated reaction network. 
Ion complexes, which are formed as a result of an interaction with water molecules, can actively interact with the products of radiolysis, namely, with the corresponding radicals $\mathrm{OH}^{-}$or molecular compounds $\mathrm{H}_{2} \mathrm{O}_{2}$ and $\mathrm{HO}_{2}$. These chemical reactions should be taken into account along with those described above. It should also be noted that uranyl can form stable complexes with anions, like $\mathrm{NO}_{3}^{-}, \mathrm{Cl}^{-}, \mathrm{SO}_{4}^{2-}, \mathrm{OH}^{-}, \mathrm{CO}_{3}^{2-}$. Experimental ultrafiltration investigations [43] show that for some definite concentrations of $\mathrm{OH}^{-}$ions the six-valent uranium in the solution is in a colloidal state. Taking into account an excess of $\mathrm{OH}^{-}$groups, we can make an assumption about the existence of the ionic complexes $\left[\mathrm{UO}_{2}\left[(\mathrm{OH})_{2} \mathrm{UO}_{2}\right]\right]_{n}^{2+}$ in such solutions, which points to their polymer structure with hydrogen bonds:

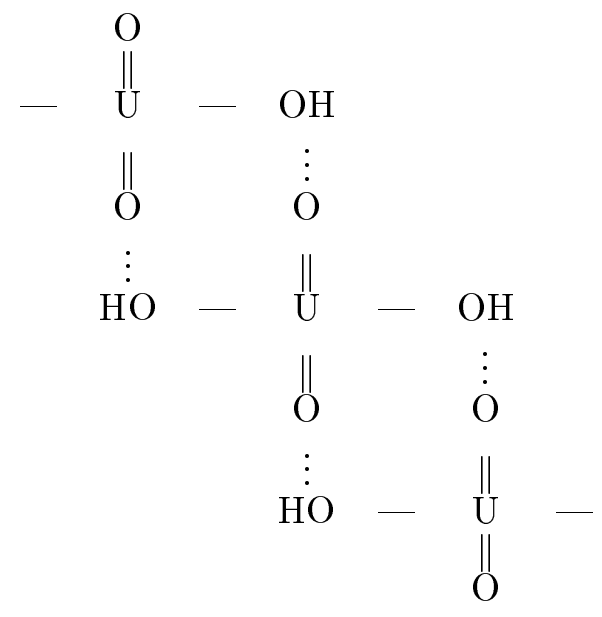

When analyzing reactions of the hydrolysis of uranyl (2.1)-(2.3), it is necessary to draw the conclusion that the excess of $\mathrm{OH}^{-}$, the yield of reactions (2.2) according to the Le-Chatelle principle, shifts the reactions to the right towards the formation of polymer complexes, particularly for $\mathrm{UO}_{2}\left(\mathrm{O} \mathrm{UO}_{2}\right)_{n}^{2+}$ with the oxygen bridges:<smiles></smiles>

But the magnitude of rate constants of the polymerization process decreases significantly with the increase of $n$, which causes the probability of chain formations with $n>4$ to be small.

As we can see, uranyl hydrolysis reactions produce hydrogen ions, as one of the sources of atomic and molecular forms of hydrogen during the interaction of water with nuclear magma. The reaction of molization $\mathrm{H}+\mathrm{H} \rightarrow \mathrm{H}_{2}$ is accompanied by the liberation of 0.34 ridbergs per molecule. This energy transforms into a kinetic energy of $\mathrm{H}_{2}$. Hydrogen molecules, unlike the molecules of the gases $\mathrm{He}, \mathrm{Ne}, \mathrm{Kr}$ and others, have a large kinetic energy and this causes large pressures in magma cavities. Thus magma is mechanically destroyed. So, we are faced here with two problems, namely, the problems of hydrogen and uranium compounds. Hydrogen causes a mechanical disintegration of the system, which increases contact with water, and concentration of uranium compounds. Uranium compounds in water 
form complexes which tend to coagulate.

Plutonium $\mathrm{Pu}$ in aqueous solutions has five degrees of oxidation: +3 , $+4,+5,+6,+7$. $\mathrm{Pu}^{4+}$ has the most interesting properties. It is in the form of hydrated ions $\mathrm{Pu}\left(\mathrm{H}_{2} \mathrm{O}\right)_{6-8}^{4+}$ in polymer-acidic solutions. Also for some concentrations of $\mathrm{Pu}$, when $\mathrm{pH}$ of the solutions increases, the hydrolysis of $\mathrm{Pu}^{4+}$ ions leads to the formation of mononuclear hydroxocomplexes $\mathrm{Pu}(\mathrm{OH})^{3+}, \mathrm{Pu}(\mathrm{OH})_{2}^{2+}$, which further can exhibit polymeric and colloid properties $[43,47]$. The hydrolysis of $\mathrm{Pu}(4)$ takes place at the concentrations of $\mathrm{H}^{+}$ions less than $0.3 \mathrm{M}$ :

$$
\mathrm{Pu}^{4+}+\mathrm{H}_{2} \mathrm{O} \leftrightarrows \mathrm{PuOH}^{3+}+\mathrm{H}^{+}
$$

Here we have to distinguish between two types of reaction products: monomeric hydrated ions of $\mathrm{Pu}(\mathrm{OH})_{n}^{(4-n)+}$ type and products of polymerization, which are formed at the same values of acidity. A slow decrease of acidity in the region of $\mathrm{H}^{+}$hydrolysis below $0.3 \mathrm{M}$ helps the formation of polymers. The dissolving of acidic solutions with water causes an instantaneous local decrease of acidity to the values favourable for polymerization. The formation of polymers is also accelerated when moderately acidic solutions of plutonium $\mathrm{Pu}(4)$ are heated [47]. The process of polymerization is accompanied by polarization of a water molecule by two plutonium ions.

Six-valent plutonium, producing plutonyl $\mathrm{PuO}_{2}^{2+}$ with oxygen, actively hydrolyses in water according to the reactions:

$$
\begin{aligned}
\mathrm{PuO}_{2}^{2+}+\mathrm{H}_{2} \mathrm{O} & \leftrightarrows \mathrm{PuO}_{2}(\mathrm{OH})^{+}+\mathrm{H}^{+}, \\
\mathrm{PuO}_{2}(\mathrm{OH})^{+}+\mathrm{H}_{2} \mathrm{O} & \leftrightarrows \mathrm{PuO}_{2}(\mathrm{OH})_{2}+\mathrm{H}^{+}, \\
\mathrm{PuO}_{2}(\mathrm{OH})^{+}+\mathrm{PuO}_{2}(\mathrm{OH})_{2} & \leftrightarrows\left(\mathrm{PuO}_{2}\right)_{2}(\mathrm{OH})_{3}^{+}, \\
\mathrm{PuO}_{2}(\mathrm{OH})_{2}+\mathrm{H}_{2} \mathrm{O} & \leftrightarrows \mathrm{PuO}_{2}(\mathrm{OH})_{3}^{-}+\mathrm{H}^{+} \\
\mathrm{PuO}_{2}(\mathrm{OH})_{2}+\mathrm{PuO}_{2}(\mathrm{OH})_{3}^{-} & \leftrightarrows\left(\mathrm{PuO}_{2}\right)_{2}(\mathrm{OH})_{5}^{-}
\end{aligned}
$$

At some particular values of $\mathrm{pH}$ this leads to the formation of colloidal complexes and polymer structures.

The presence of $\mathrm{Fe}^{3+}$ and $\mathrm{CO}_{3}^{2-}$ ions in aqueous solutions causes alkalization of uranium from nuclear magma into water. As it was mentioned, observations, which had been made since 1990, showed a creation of needlelike crystals of uranium minerals $\mathrm{UO}_{2} \mathrm{CO}_{3}, \mathrm{Na}_{4} \mathrm{UO}_{2}\left(\mathrm{CO}_{3}\right)_{3}$.

The formation of the latter mineral can be represented by the following reactions:

$$
\begin{aligned}
\mathrm{UO}_{2}+\mathrm{O}+3 \mathrm{CO}_{3}^{2-}+\mathrm{H}_{2} \mathrm{O} & \rightarrow \mathrm{UO}_{2}\left(\mathrm{CO}_{3}\right)_{3}^{4-}+2 \mathrm{OH}^{-}, \\
\mathrm{UO}_{2}+2 \mathrm{OH}+3 \mathrm{CO}_{3}^{2-} & \rightarrow \mathrm{UO}_{2}\left(\mathrm{CO}_{3}\right)_{3}^{4-}+2 \mathrm{OH}^{-},
\end{aligned}
$$

with further creation of the complex

$$
\left(\mathrm{UO}_{2} \mathrm{CO}_{3}\right)_{3}^{4-}+4 \mathrm{Na}^{+} \rightarrow \mathrm{Na}_{4} \mathrm{UO}_{2}\left(\mathrm{CO}_{3}\right)_{3},
$$

that causes the formation of the mineral $\mathrm{Na}_{4} \mathrm{UO}_{2}\left(\mathrm{CO}_{3}\right)_{3}$ on the surface of the nuclear magma.

Three-valent $\mathrm{Fe}^{3+}$ is known to be a good oxidant:

$$
\mathrm{UO}_{2}+2 \mathrm{Fe}^{3+} \rightarrow \mathrm{UO}_{2}^{2+}+2 \mathrm{Fe}^{2+} .
$$


This reaction also causes alkalization of uranium from nuclear magma to water. The process of alkalization of uranium from nuclear magma to water can run actively, because $\mathrm{UO}_{2}$ reacts with $\mathrm{OH}$ radicals which are formed in the process of radiolysis and they are in excess in aqueous solutions:

$$
\mathrm{UO}_{2}+2 \mathrm{OH} \rightarrow \mathrm{UO}_{2}^{2+}+2 \mathrm{OH}^{-} .
$$

Obviously, in the process of destruction of nuclear magma, the whole parts of $\mathrm{UO}_{2}$ pills (fragments of the destroyed fuel elements, which got into the alloy of nuclear fuel in the process of its cooling) can fall into water. Oxidation reactions of $\mathrm{UO}_{2}$ by ion $\mathrm{Fe}^{3+}$ and radicals $\mathrm{O}$ and $\mathrm{OH}$ in water will be accompanied by the yield of uranyl ions to water. Further, uranyl $\mathrm{UO}_{2}^{2+}$ will be hydrolysed. Thus, on the basis of radioactive elements solutions, which are typical of the object, it is necessary to analyze and then calculate chemical reactions of plutonyl and uranyl polymerization, reaction of hydrolysis, reactions with the participation of $\mathrm{OH}$ radicals and ions $\mathrm{Fe}^{3+}$. Besides, it is very important to calculate chemical reactions which yield a sedimentation of uranium and plutonium and to investigate their transfer into water solutions.

It is necessary to note that all the mentioned above reactions of hydrolysis and alkalization are of the type

$$
\mathrm{A}_{j}+\mathrm{B}_{j} \leftrightarrows \mathrm{C}_{j}+\mathrm{D}_{j},
$$

and the change in the concentration of the components in a solution versus time, as a result of the diffusion and chemical reactions, can be described in the diffuse approximation by the following equations:

$$
\begin{aligned}
& \frac{\mathrm{d}}{\mathrm{d} t} n_{\mathrm{A}_{j}}=D_{\mathrm{A}_{j}} \nabla^{2} n_{\mathrm{A}_{j}}-K_{\mathrm{A}_{j} \mathrm{~B}_{j}} n_{\mathrm{A}_{j}} n_{\mathrm{B}_{j}}+K_{\mathrm{C}_{j} \mathrm{D}_{j}} n_{\mathrm{C}_{j}} n_{\mathrm{D}_{j}}, \\
& \frac{\mathrm{d}}{\mathrm{d} t} n_{\mathrm{B}_{j}}=D_{\mathrm{B}_{j}} \nabla^{2} n_{\mathrm{B}_{j}}-K_{\mathrm{A}_{j} \mathrm{~B}_{j}} n_{\mathrm{A}_{j}} n_{\mathrm{B}_{j}}+K_{\mathrm{C}_{j} \mathrm{D}_{j}} n_{\mathrm{C}_{j}} n_{\mathrm{D}_{j}}, \\
& \frac{\mathrm{d}}{\mathrm{d} t} n_{\mathrm{C}_{j}}=D_{\mathrm{C}_{j}} \nabla^{2} n_{\mathrm{C}_{j}}+K_{\mathrm{A}_{j} \mathrm{~B}_{j}} n_{\mathrm{A}_{j}} n_{\mathrm{B}_{j}}-K_{\mathrm{C}_{j} \mathrm{D}_{j}} n_{\mathrm{C}_{j}} n_{\mathrm{D}_{j}}, \\
& \frac{\mathrm{d}}{\mathrm{d} t} n_{\mathrm{D}_{j}}=D_{\mathrm{D}_{j}} \nabla^{2} n_{\mathrm{D}_{j}}+K_{\mathrm{A}_{j} \mathrm{~B}_{j}} n_{\mathrm{A}_{j}} n_{\mathrm{B}_{j}}-K_{\mathrm{C}_{j} \mathrm{D}_{j}} n_{\mathrm{C}_{j}} n_{\mathrm{D}_{j}},
\end{aligned}
$$

where $D_{l}$ and $k_{l f}$ correspond to the diffusion coefficients of the components and constants of reactions between the components in the solution.

When describing the disruption of the silicate matrix, an important question is to elucidate destructive mechanisms, first of all for magma surface undergoing interaction with water. Interplay of an aqueous solution with a glassy surface is accompanied by a set of interconnected physical and chemical processes: ion-exchange mutual diffusion, diffusion of ions $\mathrm{H}^{+}$ or $\mathrm{H}_{3} \mathrm{O}^{+}$, hydrolysis of the silicon-oxygen network and its corrosion, formation of pores and cracks. According to [48] they may be briefly described with the aid of chemical rections, namely, by the ion-exchange diffusion:

$$
\mathrm{L}^{+}+\equiv \mathrm{SiO}^{-} \mathrm{M}^{+} \rightleftarrows \equiv \mathrm{SiO}^{-} \mathrm{L}^{+}+\mathrm{M}^{+}
$$

As a result of the reaction (2.11), an equilibrium point is shifted, in fact, entirely to the right creating the hydrated complexes $\equiv \mathrm{SiOH} \cdots \mathrm{OH}$. Leaching and formation of the first hydrated layer occurs, which interacts afterwards with a glassy surface according to the reaction:

$$
\equiv \mathrm{SiO}^{-} \mathrm{M}^{+}+\equiv \mathrm{SiOH} \rightleftarrows \equiv \mathrm{SiOH}+\equiv \mathrm{SiO}^{-} \mathrm{M}^{+}
$$


In this manner the ion-exchange layer is formed with the inherent mutual diffusion of ions $\mathrm{H}^{+}$and $\mathrm{M}^{+}$. The interaction of water molecules with a silicate surface can be described by the chemical reactions

$$
\equiv \mathrm{SiO}^{-} \mathrm{M}^{+}+\mathrm{H}_{2} \mathrm{O} \rightleftarrows \equiv \mathrm{SiOH}+\mathrm{OH}^{-}+\mathrm{M}^{+}
$$

which results in the outlet of metal ions into the solution, while hydroxide complexes $\mathrm{OH}^{-}$take part in further reactions of the depolymerization of the silicon-oxygen network.

$$
\begin{array}{rlrl}
\equiv \mathrm{Si}-\mathrm{O}-\mathrm{Si} \equiv+\mathrm{OH}^{-} & \rightleftarrows \equiv \mathrm{SiO}^{-}+\equiv \mathrm{SiOH} & \\
\equiv \mathrm{SiO}^{-}+\equiv \mathrm{SiOH}+\mathrm{H}_{2} \mathrm{O} & \rightleftarrows 2 \equiv \mathrm{SiOH}^{-\mathrm{OH}^{-}} \quad \text { and so on }
\end{array}
$$

Reactions of this kind can proceed from a glassy magma surface to an alkali active solution ( $\mathrm{pH}=9 \div 11$ for the reservoirs of the "Shelter" object). Apart from reactions [48], water molecules are able to destroy the silicon-oxygen network due to the interaction between oxygen ions of water and Si atoms, and simultaneously between $\mathrm{H}^{+}$ions and oxygen atoms of silicon-oxygen network $\equiv \mathrm{Si}-\mathrm{O}-\mathrm{H}$

$$
\equiv \mathrm{Si}-\mathrm{O}-\mathrm{Si} \equiv+\mathrm{H}-\mathrm{OH} \rightarrow \equiv \mathrm{Si}-\mathrm{O} \cdots \mathrm{Si} \equiv+\mathrm{H} \cdots \mathrm{OH} \rightarrow \equiv \mathrm{Si}-\mathrm{O}-\mathrm{H}+\equiv \mathrm{Si}-\mathrm{OH},
$$

A set of reactions (2.13)-(2.16) represents hydrolysis and depolymerization of the silicon-oxygen network. It brings about the formation of hydrated complexes $=\mathrm{Si}(\mathrm{OH})_{2},-\mathrm{Si}(\mathrm{OH})_{3}, \mathrm{Si}(\mathrm{OH})_{4}, \mathrm{Si}(\mathrm{OH})_{6}^{2-}$ which are transferred to the solution. In such a manner the corrosion of the silicon-oxygen network occurs being enhanced by hydrogen ions $\mathrm{H}^{+}$, hydrated complexes $\mathrm{OH}^{-}$, which arise additionally as a result of radiolysis, hydrolysis and hydration of uranium $\mathrm{UO}_{2}$, plutonium $\mathrm{PuO}_{2}$ and other oxides [26,27,30,31].

When ions of uranyl $\mathrm{UO}_{2}^{2+}$ are present in the near-surface layer, which can be manifested by its yield from nuclear magma, the following reactions with hydrated silicium complexes are possible:

$$
\begin{aligned}
\mathrm{UO}_{2}^{2+}+2 \mathrm{Si}(\mathrm{OH}) & \rightleftarrows \mathrm{UO}_{2}(\mathrm{OSi})_{2}+2 \mathrm{H}^{+}, \\
\mathrm{UO}_{2}^{2+}+\mathrm{H}_{2} \mathrm{O} & \rightleftarrows\left[\mathrm{UO}_{2} \mathrm{OH}\right]^{+}+\mathrm{H}^{+}, \\
{\left[\mathrm{UO}_{2} \mathrm{OH}\right]^{+}+2 \mathrm{Si}(\mathrm{OH}) } & \rightleftarrows \mathrm{UO}_{2}(\mathrm{OSi})_{2}+\mathrm{H}^{+}+\mathrm{H}_{2} \mathrm{O}, \\
{\left[\mathrm{UO}_{2} \mathrm{OH}\right]^{+}+\mathrm{SiOH} } & \rightleftarrows \mathrm{UO}_{2}(\mathrm{OH})(\mathrm{OSi})+\mathrm{H}^{+},
\end{aligned}
$$

during which hydrogen ions, that can participate in reactions (2.11), are being released.

For the description of interplay of an aqueous solution with glassy nuclear magma according to reactions (2.11)-(2.16) we need to formulate a physical model to research structural functions, particle diffusion from one phase to another and reaction constants. The prelude of any microscopic treatment is structural information in the form of density profiles and higher distribution functions.

Active elements are supposed to be present in water in small amounts. Within this model the active elements particles $\left(\mathrm{UO}_{2}^{2+}, \mathrm{Cs}^{+}, \mathrm{Sr}^{2+}\right)$ are considered as charged hard spheres having an overall charge compensated according to the electroneutrality condition by negative $\mathrm{OH}^{-}$-groups in a continuous medium with the dielectric constant $\varepsilon=81$ (water).

Active aqueous solutions inside the "Shelter" object contact mostly with nuclear magma, concrete, clay and numerous construction materials. To 
predict destruction and investigate diffusion of active particles, it is necessary to know the structure of a solution near these materials. The problem reduces to the treatment of the solution model near a hard wall outlined above, which, along with a solvent, is a continuous medium with the dielectric constant $\varepsilon=1 \div 15$ (glassy-like medium, clay, concrete). In this approach profiles are affected by structural ordering caused by their sizes and the presence of surface, as well as electrostatic images most pronounced at small distances. However, their consecutive consideration is a fairly intricate problem. So far we used the first equation of the Bogolubov-Green-Yvon hierarchy, modified to describe image charges. The latter are assumed to be fictitious charged particles inside the wall (glassy medium, clay, concrete, volume $V^{\prime}$ ), which have the charges $\frac{\varepsilon_{p}-\varepsilon_{c}}{\varepsilon_{p}+\varepsilon_{c}} Z_{i} e$ and sizes $\sigma_{i}$, whereas $Z_{i} e, \sigma_{i}$ are charges and sizes of particles in the solution (volume $V$ ). Applying the method given in [49], we arrive at the following equation:

$$
\begin{aligned}
& \frac{\mathrm{d} f_{a}\left(z_{1}\right)}{\mathrm{d} z_{1}}+\frac{\mathrm{d} U_{1}^{a}\left(z_{1}\right)}{\mathrm{d} z_{1}} f_{a}\left(z_{1}\right) \\
& +\sum_{c} \rho_{c} \int_{V} \mathrm{~d} \boldsymbol{r}_{2 c} \frac{\partial}{\partial z_{1}}\left(U_{\mathrm{hS}}^{a c}\left(r_{12}\right)+U_{\mathrm{C}}^{a c}\left(r_{12}\right)\right) F_{a c}\left(z_{1 a}, z_{2 c}, r_{2 c}\right) \\
& +\sum_{c} \rho_{c}^{\prime} \int_{V^{\prime}} \mathrm{d} \boldsymbol{r}_{2 c}^{\prime} \frac{\partial}{\partial z_{1}} U_{\mathrm{im}}^{a c}\left(r_{12}^{\prime}\right) F_{a c}^{\prime}\left(z_{1 a}, z_{2 c}^{\prime}, r_{2 c}^{\prime}\right)=0,
\end{aligned}
$$

whereas $f_{a}\left(z_{1}\right), U_{1}^{a}\left(z_{1}\right)$ are the profile and interaction potential of the $a$ th species particle with the wall; $F_{a c}, U_{\mathrm{hs}}^{a c}, U_{\mathrm{C}}^{a c}, U_{\mathrm{im}}^{a c}$ are the binary distribution function for the particles of species $a, c$, hard sphere potentials, Coulomb interaction between the particles and between the particles and the images, respectively; $\rho_{c}, \rho_{c}^{\prime}$ are the densities of species $c$ particles and their images. It is easily seen that the second integral term takes into account image effects on equal terms. But at small concentrations the integral terms are minor (the pair correlation is not essential), so the ionic distribution near the surface is determined by the potential $U_{1}^{a}\left(z_{1}\right)$ that is advantageously used as a screened potential. The problem of the point particles screened potential near a hard wall has a rigorous analytical solution $[2,50]$. In the case of ion-ion interaction the result is as follows:

$$
g\left(\boldsymbol{r}_{1}, \boldsymbol{r}_{2}\right)=\mp \frac{Z_{1} Z_{2} e^{2}}{\varepsilon_{p}}\left\{\frac{\mathrm{e}^{-\kappa r_{12}}}{r_{12}}+\frac{\varepsilon_{p}-\varepsilon_{\mathrm{c}}}{\varepsilon_{p}+\varepsilon_{\mathrm{c}}} \frac{\mathrm{e}^{-\kappa r_{12}^{\prime}}}{r_{12}^{\prime}}\right\},
$$

with $r_{12}$ - a distance between the particles, $r_{12}^{\prime}$ - that between the first particle and the image of the second one. It is evident that the potential consists of the bulk part dependent on $r_{12}$ and the surface one. The problem of the bulk screened potential evaluation for an arbitrary amount of ions, having distinct sizes and valences, is solved in [50]. We make use of the result for small concentrations in view of the fact that the potential of an inhomogeneous system is expressed through bulk ones, as is seen from (2.18). Thus,

$$
U_{1}^{a}\left(z_{1}\right)=\frac{\varepsilon_{p}-\varepsilon_{c}}{\varepsilon_{p}+\varepsilon_{c}} \frac{\left(Z_{1}^{a} e\right)^{2}}{\varepsilon_{p}} \frac{1}{2 z}\left[\frac{2 \Gamma}{\kappa}\right]^{2} \exp \left\{-2 \Gamma\left(2 z-\sigma_{a}\right)\right\}, \quad z>\sigma_{a} / 2,
$$

in which $2 \Gamma-$ a new screening radius to be specified by the following equation 
system:

$$
\begin{gathered}
4 \Gamma^{2}=\frac{e^{2}}{\varepsilon_{p}} \sum_{a} \rho_{a} X_{a}^{2}, \quad X_{a}=\frac{Z_{a}-\frac{\pi}{2} \frac{\sigma_{a}^{2}}{1-\eta} P_{m}}{1+\Gamma \sigma_{a}}, \\
P_{m}=\frac{\sum_{a} \frac{\rho_{a} \sigma_{a} Z_{a}}{1+\Gamma \sigma_{a}}}{1+\frac{\pi}{2(1-\eta)} \sum_{a} \frac{\rho_{a} \sigma_{a}^{3}}{1+\Gamma \sigma_{a}}}, \quad \eta=\frac{\pi}{6} \sum_{a} \rho_{a} \sigma_{a}^{3}, \quad \rho_{a}=N_{a} / V,
\end{gathered}
$$

where $a$ stands for active ions including negative $\mathrm{OH}^{-}$-groups with a density to satisfy the general electroneutrality condition for the system

$$
\sum_{a} \rho_{a} Z_{a}^{2}=0
$$

Then the solution of (2.17) under the condition $f_{a}(\infty)=1$ is the following:

$$
f_{a}(z)=\exp \left(-U_{1}^{a}(z)\right) .
$$

For a pair distribution function the superposition approximation yields:

$$
\begin{gathered}
F_{\alpha \beta}\left(z_{1}, z_{2}, r\right)=f_{\alpha}\left(z_{1}\right) f_{\beta}\left(z_{2}\right) F_{\alpha \beta}(\boldsymbol{r})= \\
\exp \left(-U_{1}^{\alpha}\left(z_{1}\right)-U_{1}^{\beta}\left(z_{2}\right)+g\left(z_{1}, z_{2}, r\right)\right) .
\end{gathered}
$$

Figure 1 shows qualitatively the two-body functions for ions $\mathrm{UO}_{2}^{2+}, \mathrm{Cs}^{+}$ estimated at various concentrations with the aid of (2.21). There are 10 pair distribution functions in the system under consideration. We restrict ourselves to those for identical radioactive particles. It means that we have computed $F_{\alpha \alpha}, \alpha=\mathrm{UO}_{2}^{2+}, \mathrm{Cs}^{+}$. Since $F_{\alpha \beta}$ depends, in general, on three parameters, it is convenient to fix particle 1 , for example, in contact with the magma wall. As the dependence on $z_{1}$ cannot be plotted, the figures exhibit the behaviour of functions $F^{\prime}=F_{\alpha \alpha} / f_{\alpha}\left(z_{1}\right)$. And finally, the position of the second particle with respect to the fixed one is defined via distance $r$ and angle $\theta$ rather than $z_{2}$, so that $z_{2}=z_{1}+r \cos \theta$. Such functions $F^{\prime}(r, \theta)$ are plotted in figure 1.

It can be seen that small concentrations of active elements result in an essential wall effect even at long distances, while large ones bring about screening due to which the system quickly attains bulk properties. The overall drop of functions for all the elements at angles more than $70^{\circ}$ is the evidence of a negative adsorbtion occurring in a thin near interface layer of magma. The phenomenon might terminate the penetration of radioactive matter into the grounds.

\subsection{Spatially inhomogeneous diffusion model}

To describe the diffusion of complex particles from nuclear magma into water realistically, we are going to complicate the system by considering a model comprising $M$ species with $N_{a}$ particles of each species, which combine $X_{\alpha}$ sites (each site carries the charge $e z_{\alpha}^{a}$ ) interacting between themselves and water molecules. The subsystem "water" with the dielectric constant $\varepsilon_{\mathrm{B}}$ is regarded as a total combination of water molecules $\mathrm{H}_{2} \mathrm{O}$ and ionic radicals, in particular, hydrogen ions $\mathrm{H}^{+}$and complex $\mathrm{OH}^{-}$, and labelled 
as particles of $s$ species formed by $X_{\alpha}$ charged sites in volume $V_{2}$. It is clear that the aqueous solution can harbour other ions or molecular complexes interacting with nuclear magma particles. At a certain stage of studies they might be taken into account. The change in the charged sites density, which should be incorporated to create an active element (e.g. those in ionic form $\mathrm{UO}_{2}^{2+}, \mathrm{PuO}_{2}^{2+}$ ) in the silicate matrix, can be described by generalized diffusion equations for the two-phase system "nuclear magma - water". Similar equations were obtained in our papers [51,52]. In the case of a quasiequilibrium diffusion this equation system is as follows:
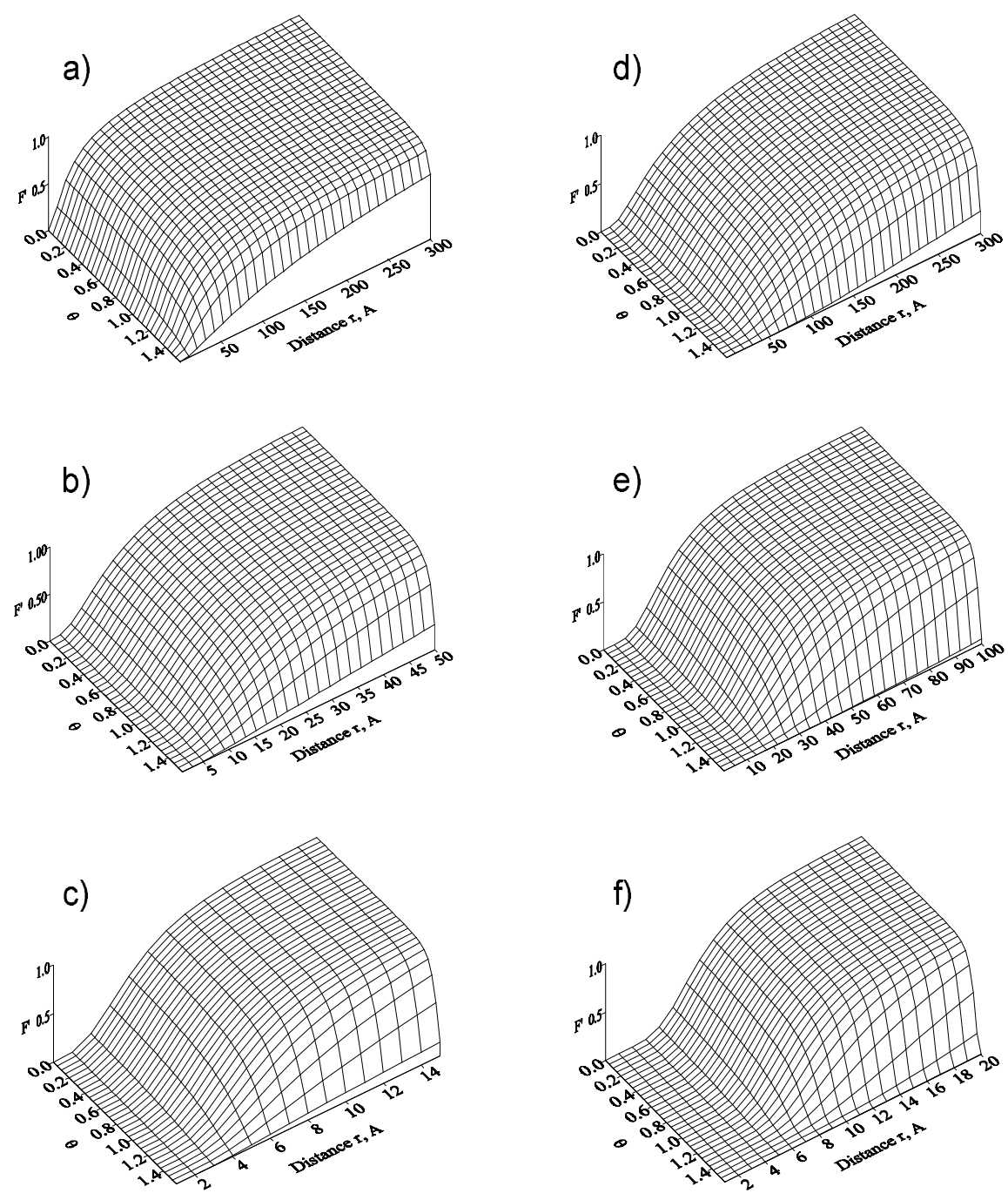

Figure 1. Pair distribution functions $F^{\prime}(r, \theta)$ (see text) at various concentrations: a) $1 \mathrm{mg} / \mathrm{l}$ of Cs, b) $10 \mathrm{mg} / \mathrm{l}$ of Cs, c) $1 \mathrm{~g} / \mathrm{l}$ of Cs; d) $1 \mathrm{mg} / \mathrm{l}$ of $\mathrm{UO}_{2}$, e) $10 \mathrm{mg} / \mathrm{l}$ of $\mathrm{UO}_{2}$, f) $1 \mathrm{~g} / \mathrm{l}$ of $\mathrm{UO}_{2}$. 
a) the phase "nuclear magma", volume $V_{1}$ :

$$
\begin{aligned}
& \frac{\partial}{\partial t} \delta n_{1}^{\alpha a}\left(\boldsymbol{r}_{1} ; t\right)= \\
& -\sum_{\beta, b} \int_{V_{1}} \mathrm{~d} \boldsymbol{r}_{1}^{\prime} \int_{-\infty}^{t} \mathrm{~d} t^{\prime} \mathrm{e}^{\varepsilon\left(t^{\prime}-t\right)} \frac{\partial}{\partial \boldsymbol{r}_{1}} D_{11}^{\alpha a, \beta b}\left(\boldsymbol{r}_{1}, \boldsymbol{r}_{1}^{\prime} ; t, t^{\prime}\right) \frac{\partial}{\partial \boldsymbol{r}_{1}^{\prime}} \delta n_{1}^{\beta b}\left(\boldsymbol{r}_{1}^{\prime} ; t^{\prime}\right) \\
& -\sum_{\beta, b} \int_{V_{2}} \mathrm{~d} \boldsymbol{r}_{2}^{\prime} \int_{-\infty}^{t} \mathrm{~d} t^{\prime} \mathrm{e}^{\varepsilon\left(t^{\prime}-t\right)} \frac{\partial}{\partial \boldsymbol{r}_{1}} D_{12}^{\alpha a, \beta b}\left(\boldsymbol{r}_{1}, \boldsymbol{r}_{2}^{\prime} ; t, t^{\prime}\right) \frac{\partial}{\partial \boldsymbol{r}_{2}^{\prime}} \delta n_{2}^{\beta b}\left(\boldsymbol{r}_{2}^{\prime} ; t^{\prime}\right) \\
& -\sum_{s} \int_{V_{2}} \mathrm{~d} \boldsymbol{r}_{2}^{\prime} \int_{-\infty}^{t} \mathrm{~d} t^{\prime} \mathrm{e}^{\varepsilon\left(t^{\prime}-t\right)} \frac{\partial}{\partial \boldsymbol{r}_{1}} D_{12}^{\alpha a, \beta s}\left(\boldsymbol{r}_{1}, \boldsymbol{r}_{2}^{\prime} ; t, t^{\prime}\right) \frac{\partial}{\partial \boldsymbol{r}_{2}^{\prime}} \delta n_{2}^{\beta s}\left(\boldsymbol{r}_{2}^{\prime} ; t^{\prime}\right) \\
& +\sum_{\beta, b} A_{1}^{\alpha a \beta b}(\boldsymbol{r}, t) \delta n_{1}^{\beta b}\left(\boldsymbol{r}_{1} ; t\right)-A_{1}^{\alpha a}(\boldsymbol{r}, t) \delta n_{1}^{\alpha a}\left(\boldsymbol{r}_{1} ; t\right)
\end{aligned}
$$

b) the phase "water", volume $V_{2}$ :

$$
\begin{aligned}
& \frac{\partial}{\partial t} \delta n_{2}^{\alpha s}\left(\boldsymbol{r}_{2} ; t\right)= \\
& -\sum_{\beta, b} \int_{V_{1}} \mathrm{~d} \boldsymbol{r}_{1}^{\prime} \int_{-\infty}^{t} \mathrm{~d} t^{\prime} \mathrm{e}^{\varepsilon\left(t^{\prime}-t\right)} \frac{\partial}{\partial \boldsymbol{r}_{2}} D_{21}^{\alpha s, \beta b}\left(\boldsymbol{r}_{2}, \boldsymbol{r}_{1}^{\prime} ; t, t^{\prime}\right) \frac{\partial}{\partial \boldsymbol{r}_{1}^{\prime}} \delta n_{1}^{\beta b}\left(\boldsymbol{r}_{1}^{\prime} ; t^{\prime}\right) \\
& -\sum_{\beta, b} \int_{V_{2}} \mathrm{~d} \boldsymbol{r}_{2}^{\prime} \int_{-\infty}^{t} \mathrm{~d} t^{\prime} \mathrm{e}^{\varepsilon\left(t^{\prime}-t\right)} \frac{\partial}{\partial \boldsymbol{r}_{2}} D_{22}^{\alpha s, \beta b}\left(\boldsymbol{r}_{2}, \boldsymbol{r}_{2}^{\prime} ; t, t^{\prime}\right) \frac{\partial}{\partial \boldsymbol{r}_{2}^{\prime}} \delta n_{2}^{\beta b}\left(\boldsymbol{r}_{2}^{\prime} ; t^{\prime}\right) \\
& -\sum_{s^{\prime}} \int_{V_{2}} \mathrm{~d} \boldsymbol{r}_{2}^{\prime} \int_{-\infty}^{t} \mathrm{~d} t^{\prime} \mathrm{e}^{\varepsilon\left(t^{\prime}-t\right)} \frac{\partial}{\partial \boldsymbol{r}_{2}} D_{22}^{\alpha s, \beta s^{\prime}}\left(\boldsymbol{r}_{2}, \boldsymbol{r}_{2}^{\prime} ; t, t^{\prime}\right) \frac{\partial}{\partial \boldsymbol{r}_{2}^{\prime}} \delta n_{2}^{\beta s^{\prime}}\left(\boldsymbol{r}_{2}^{\prime} ; t^{\prime}\right),
\end{aligned}
$$

and

$$
\begin{aligned}
& \frac{\partial}{\partial t} \delta n_{2}^{\alpha a}\left(\boldsymbol{r}_{2} ; t\right)= \\
& -\sum_{\beta, b} \int_{V_{1}} \mathrm{~d} \boldsymbol{r}_{1}^{\prime} \int_{-\infty}^{t} \mathrm{~d} t^{\prime} \mathrm{e}^{\varepsilon\left(t^{\prime}-t\right)} \frac{\partial}{\partial \boldsymbol{r}_{2}} D_{21}^{\alpha a, \beta b}\left(\boldsymbol{r}_{2}, \boldsymbol{r}_{1}^{\prime} ; t, t^{\prime}\right) \frac{\partial}{\partial \boldsymbol{r}_{1}^{\prime}} \delta n_{1}^{\beta b}\left(\boldsymbol{r}_{1}^{\prime} ; t^{\prime}\right) \\
& -\sum_{\beta, b} \int_{V_{2}} \mathrm{~d} \boldsymbol{r}_{2}^{\prime} \int_{-\infty}^{t} \mathrm{~d} t^{\prime} \mathrm{e}^{\varepsilon\left(t^{\prime}-t\right)} \frac{\partial}{\partial \boldsymbol{r}_{2}} D_{22}^{\alpha a, \beta b}\left(\boldsymbol{r}_{2}, \boldsymbol{r}_{2}^{\prime} ; t, t^{\prime}\right) \frac{\partial}{\partial \boldsymbol{r}_{2}^{\prime}} \delta n_{2}^{\beta b}\left(\boldsymbol{r}_{2}^{\prime} ; t^{\prime}\right) \\
& -\sum_{s} \int_{V_{2}} \mathrm{~d} \boldsymbol{r}_{2}^{\prime} \int_{-\infty}^{t} \mathrm{~d} t^{\prime} \mathrm{e}^{\varepsilon\left(t^{\prime}-t\right)} \frac{\partial}{\partial \boldsymbol{r}_{2}} D_{22}^{\alpha a, \beta s}\left(\boldsymbol{r}_{2}, \boldsymbol{r}_{2}^{\prime} ; t, t^{\prime}\right) \frac{\partial}{\partial \boldsymbol{r}_{2}^{\prime}} \delta n_{2}^{\beta s}\left(\boldsymbol{r}_{2}^{\prime} ; t^{\prime}\right) \\
& +\sum_{\beta, b} A_{2}^{\alpha a \beta b}(\boldsymbol{r}, t) \delta n_{2}^{\beta b}\left(\boldsymbol{r}_{2} ; t\right)-A_{2}^{\alpha a}(\boldsymbol{r}, t) \delta n_{2}^{\alpha a}\left(\boldsymbol{r}_{2} ; t\right)
\end{aligned}
$$

where $\varepsilon$ tends to +0 after the thermodynamical limit. 
The last two terms in these equations describe a radionuclide density variation in time because of nuclear transformations promoted by neutrons and spontaneous decay. The first one describes the formation of a radionuclide in the site $\alpha a$ from all the other nuclei in sites $\beta b$, as a result of $(n, \gamma)$, $\alpha$-, $\beta$-decays, as well as $(n, f)$ reactions if the relevant $\alpha a$-site radionuclide belongs to fission products. The second term describes the decay of an $\alpha a$-site radionuclide under the action of neutrons and natural radioactive decay. Functions $A^{\alpha \beta}(\boldsymbol{r}, t), A^{\alpha}(\boldsymbol{r}, t)$ are rates of the reactions represented as follows:

$$
\begin{aligned}
A_{\alpha a \beta b}(\boldsymbol{r}, t) & =\int_{0}^{\infty} J(\boldsymbol{r} ; E ; t) \sigma_{\alpha a, \beta b}(E) \mathrm{d} E+L_{\alpha a, \beta b} \lambda_{\beta b}, \\
A_{\alpha a}(\boldsymbol{r}, t) & =\int_{0}^{\infty} J(\boldsymbol{r} ; E ; t) \sigma_{\alpha a}(E) \mathrm{d} E+\lambda_{\alpha a} .
\end{aligned}
$$

Here $J(\boldsymbol{r} ; E ; t)$ is the spectrum of neutron density fluxes in point $\boldsymbol{r}$ at time $t ; \sigma_{\alpha a, \beta b}(E)$ is the microscopic section of $\alpha a$-site radionuclide formation at catching neutron with energy $E$ by $\beta b$-site nucleus, $\sigma_{\alpha a}(E)$ is the microscopic section of catching a neutron with energy $E$ by $\alpha a$-site nucleus, $L_{\alpha a, \beta b}$ is the probability for the creation of an $\alpha a$-site radionuclide at radioactive decay of $\beta b$-site nucleus, $\lambda_{\alpha a}$ and $\lambda_{\beta b}$ are the decay constants of $\alpha a^{-}, \beta b_{-}$ site nuclei. The time dependence of reaction rates $A_{\alpha a, \beta b}(\boldsymbol{r}, t), A_{\alpha a}(\boldsymbol{r}, t)$ is determined by the spectrum of neutron density fluxes $J(\boldsymbol{r} ; E ; t)$ which have been calculated for FCM of the "Shelter" object in papers [18,20,21]. The neutron spatial energy distribution in its turn depends on the spatial distribution and concentration of radionuclides in the system, therefore, actually the neutron field and time variation of density of actinides or fission products are closely related.

In equations (2.22)-(2.24)

$$
\begin{aligned}
\delta n_{\xi}^{\alpha a}\left(\boldsymbol{r}_{\xi} ; t\right) & =\left\langle\delta \hat{n}_{\xi}^{\alpha a}\left(\boldsymbol{r}_{\xi}\right)\right\rangle^{t} \\
\delta \hat{n}_{\xi}^{\alpha a}\left(\boldsymbol{r}_{\xi}\right) & =\hat{n}_{\xi}^{\alpha a}\left(\boldsymbol{r}_{\xi}\right)-\left\langle\hat{n}_{\xi}^{\alpha a}\left(\boldsymbol{r}_{\xi}\right)\right\rangle_{0}, \\
\hat{n}_{\xi}^{\alpha a}\left(\boldsymbol{r}_{\xi}\right) & =\sum_{j=1}^{N_{a}} \delta\left(\boldsymbol{r}_{j}^{\alpha}-\boldsymbol{r}_{\xi}\right) .
\end{aligned}
$$

It should be remembered that the site densities $n_{\xi}^{\alpha a}\left(\boldsymbol{r}_{\xi} ; t\right)$ are not irrespective of each other as they compose complex particles and, thus,

$$
\frac{n_{\xi}^{\alpha a}\left(\boldsymbol{r}_{\xi} ; t\right)}{X_{\alpha}}=\frac{n_{\xi}^{\beta a}\left(\boldsymbol{r}_{\xi} ; t\right)}{X_{\beta}}=n_{\xi}^{a}\left(\boldsymbol{r}_{\xi} ; t\right)
$$

in which $n_{\xi}^{a}$ is related to $f_{a}$ from (2.17) through the density factor

$$
n_{\xi}^{a}=\frac{N_{a}}{V_{\xi}} f_{a}
$$

Equation (2.27) defines the density for the $\alpha$ th site carried by the $a$ th species particle in the phase $\xi=1,2 ;\langle\ldots\rangle^{t}$ is the averaging with the total 
nonequilibrium distribution function for particles of the whole system, $\langle\ldots\rangle_{0}$ is the averaging with the total equilibrium function $\rho_{0}$. Respectively,

$$
\hat{n}_{\xi}^{\beta s}\left(\boldsymbol{r}_{\xi}\right)=\sum_{l=1}^{N_{s}} \delta\left(\boldsymbol{r}_{l}^{\beta}-\boldsymbol{r}_{\xi}\right)
$$

is the microscopic density of water molecules or dissociated ions $\left(\mathrm{H}^{+}, \mathrm{OH}^{-}\right)$ and radicals. We denote

$$
\begin{array}{r}
D_{\xi f}^{\alpha a, \beta b}\left(\boldsymbol{r}_{\xi}, \boldsymbol{r}_{f}^{\prime} ; t, t^{\prime}\right)=\sum_{\gamma, c} \sum_{f^{\prime}} \int_{V_{f^{\prime}}} \mathrm{d} \boldsymbol{r}_{f^{\prime}}^{\prime \prime}\left\langle\left(1-P_{M}\right) \hat{\boldsymbol{J}}_{\xi}^{\alpha a}\left(\boldsymbol{r}_{\xi}\right) \times\right. \\
\left.\times T\left(t, t^{\prime}\right)\left(1-P_{M}\right) \hat{\boldsymbol{J}}_{f^{\prime}}^{\gamma c}\left(\boldsymbol{r}_{f^{\prime}}^{\prime \prime}\right)\right\rangle_{0}\left(\tilde{F}^{-1}\left(\boldsymbol{r}^{\prime \prime}, \boldsymbol{r}^{\prime}\right)\right)_{f^{\prime} f}^{\gamma c, \beta b}
\end{array}
$$

as generalized diffusion coefficients for charged sites, in particular, $D_{11}^{\alpha a, \beta b}$ corresponds to nuclear magma, $D_{12}^{\alpha a, \beta b}$ governs the diffusion from nuclear magma into water; $D_{22}^{\alpha a, \beta b}$ concerns water. Here

$$
\hat{\boldsymbol{J}}_{\xi}^{\alpha a}(\boldsymbol{r})=\sum_{j=1}^{N_{a}} \boldsymbol{p}_{j}^{\alpha} \delta\left(\boldsymbol{r}_{j}^{\alpha}-\boldsymbol{r}_{\xi}\right)
$$

is the momentum density for charged sites in the respective phase $\xi$,

$$
P_{M} A=\sum_{\alpha, a \xi} \sum_{\beta, b f} \int_{V_{\xi}} \mathrm{d} \boldsymbol{r}_{\xi} \int_{V_{f}} \mathrm{~d} \boldsymbol{r}_{f}^{\prime}\left\langle A \hat{n}_{\xi}^{\alpha a}\left(\boldsymbol{r}_{\xi}\right)\right\rangle_{0}\left(\tilde{F}^{-1}\left(\boldsymbol{r}, \boldsymbol{r}^{\prime}\right)\right)_{\xi f}^{\alpha a, \beta b} \hat{n}_{f}^{\beta b}\left(\boldsymbol{r}_{f}^{\prime}\right)
$$

is the Mori projection operator, $T_{0}(t)=\exp \left\{\left(1-P_{M}\right) \mathrm{i} L_{N} t\right\}$ is the time evolution operator, $\mathrm{i} L_{N}$ is the Liouville operator appropriate to the system's Hamiltonian

$$
\begin{gathered}
H=\sum_{a} \sum_{\alpha j}^{N_{a}, X_{a}} \frac{\left(p_{j}^{\alpha}\right)^{2}}{2 m_{a}}+\frac{1}{2} \sum_{a, b} \sum_{\alpha, \beta} \sum_{i, j} \Phi_{a b}\left(\boldsymbol{r}_{i j}^{\alpha \beta}\right)+\sum_{s} \sum_{i=1}^{N_{s}} \frac{p_{i}^{2}}{2 m_{s}} \\
+\frac{1}{2} \sum_{s, s^{\prime}} \sum_{i, l} \Phi_{s s^{\prime}}\left(\boldsymbol{r}_{i l}\right)+\sum_{a} \sum_{\alpha, j}^{N_{a}, X a} \sum_{s} \sum_{l=1}^{N_{s}} \Phi_{a s}\left(\boldsymbol{r}_{j l}^{\alpha}\right)+\sum_{a, \alpha, j}^{N_{a}, X_{a}} \varphi_{a}^{(1)}\left(z_{j}^{\alpha}\right),
\end{gathered}
$$

where $\Phi_{a b}\left(\boldsymbol{r}_{i j}^{\alpha \beta}\right)$ is the potential of interaction between charged sites, $\Phi_{a s}\left(\boldsymbol{r}_{j l}^{\alpha}\right)$ that for charged sites and water molecules (or ions $\mathrm{H}^{+}, \mathrm{OH}^{-}$, or radicals $\left.\mathrm{HO}_{2}, \mathrm{H}_{2} \mathrm{O}_{2}, \mathrm{H}_{2}\right), \varphi_{a}^{(1)}\left(z_{j}^{\alpha}\right)$ is the potential at the interface "nuclear magmawater". The functions $\left(\tilde{F}^{-1}\left(\boldsymbol{r}, \boldsymbol{r}^{\prime}\right)\right)_{\xi f}^{\alpha a, \beta b}$ make up the matrix $\tilde{F}^{-1}\left(\boldsymbol{r}, \boldsymbol{r}^{\prime}\right)$ inverse to $\tilde{F}\left(\boldsymbol{r}, \boldsymbol{r}^{\prime}\right)$. This latter consists of the pair equilibrium distribution functions for charged sites

$$
F_{\xi f}^{\alpha a, \beta b}\left(\boldsymbol{r}, \boldsymbol{r}^{\prime}\right)=\left\langle\hat{n}_{\xi}^{\alpha a}(\boldsymbol{r}) \hat{n}_{f}^{\beta b}\left(\boldsymbol{r}^{\prime}\right)\right\rangle_{0} .
$$

At the same time, in equations (2.22)-(2.24), $D_{21}^{\alpha s, \beta b}, D_{22}^{\alpha s, \beta b}, D_{12}^{\alpha a, \beta s}$ are the mutual diffusion coefficients for nuclear magma charged sites, water 
molecules, ions $\mathrm{H}^{+}, \mathrm{OH}^{-}$and radicals $\mathrm{H}_{2}, \mathrm{H}_{2} \mathrm{O}_{2}, \mathrm{HO}_{2}$. In the subsystem "water" it is necessary to investigate the mutual diffusion coefficients for charged sites of $\mathrm{UO}_{2}^{2+}, \mathrm{PuO}_{2}^{2+}$ and other ions and water molecules, ions $\mathrm{H}^{+}, \mathrm{OH}^{-}$and radicals $-D_{22}^{\alpha a, \beta b}, D_{22}^{\alpha a, \beta s}$ introducing the corresponding constants of chemical reactions. It is important to research on the hydration of ions $\mathrm{UO}_{2}^{2+}, \mathrm{PuO}_{2}^{2+}$ at their outlet from nuclear magma into water, because uranyl and plutonyl reveal a polymeric structure if uranium or plutonium concentration in water increases [10]. The dynamical behaviour of those combinations is indetermined in the case of enhancing uranium or plutonium concentration. But equations (2.22)-(2.24) can yield information by calculating the generalized diffusion coefficients (2.29) for the system "nuclear magma-water" and taking account of the peculiarities of interaction between the medium and the water solution. A remarkable point in the studies of diffusion coefficients $D_{\xi f}^{\alpha a, \beta b}, D_{\xi f}^{\alpha a, \beta s}$ in the subsystem "water" is the consideration of radiolysis in it, induced by $\alpha$-, $\beta$-decays and $\gamma$-radiation.

\subsection{Processes of aqueous solutions radiolysis and chemical reactions}

From the point of view of statistical theory, the aqueous solutions of radioactive elements are complex ionic-molecular systems with a long-range dipole and short-range interactions leading to the creation of chemical bonds between ions and molecular products. In such solutions it is necessary to take into account the phenomena of ions solvatation, hydratation, appearing and altering the polymer structure. These aqueous solutions are under the permanent influence of internal and external $\alpha$-, $\beta$ - and $\gamma$-radiations from FCM. That is why the state of these solutions is determined by the character of radiolysis processes which permanently change the nature of interaction between solutions particles due to the emerging of ionized tracks (domains of high concentration of $\mathrm{e}_{\mathrm{aq}}^{-}, \mathrm{H}_{2} \mathrm{O}^{+}, \mathrm{H}_{\mathrm{aq}}^{+}, \mathrm{OH}_{\mathrm{aq}}^{-}$ions).

In the general case the interaction process between ionizing particles $(\alpha-, \beta-, \gamma$-radiation, uranium and plutonium decay products) and water molecules could be divided into three stages: physical, physico-chemical and chemical [53-58].

At the physical stage, during the time interval of $\sim 10^{-16}$ sec after the ionizing particle had passed through the excited $\mathrm{H}_{2} \mathrm{O}^{*}$ and superexcited $\mathrm{H}_{2} \mathrm{O}^{* *}$, water molecules and ions $\mathrm{H}_{2} \mathrm{O}^{+}$were created

$$
\mathrm{H}_{2} \mathrm{O}^{*} \rightarrow \mathrm{H}_{2} \mathrm{O}^{+}+\mathrm{e}_{\mathrm{aq}}^{-},
$$

where the asterisk $*$ denotes an excited molecule. The excited electrons during the time interval of about $10^{-15}$ sec have been hydrated and interacted with water molecules

$$
\mathrm{e}_{\mathrm{aq}}^{-}+\mathrm{H}_{2} \mathrm{O} \rightarrow \mathrm{H}+\mathrm{OH}^{-} .
$$

$\mathrm{H}_{2} \mathrm{O}^{+}$ions also interact with water molecules:

$$
\mathrm{H}_{2} \mathrm{O}^{+}+\mathrm{H}_{2} \mathrm{O} \rightarrow \mathrm{H}_{3} \mathrm{O}^{+}+\mathrm{OH} .
$$

After $10^{-14}$ sec the dissociation of excited water molecules occurs:

$$
\mathrm{H}_{2} \mathrm{O}^{\prime} \rightarrow \mathrm{H}^{+}+\mathrm{OH}^{-} \text {. }
$$


In the case of a large irradiation dose (the excitation energy of water molecules is about $10 \div 17 \mathrm{eV}$ ) the hydrogen and oxygen radicals could be created $10^{-14}$ sec after the process had started:

$$
\mathrm{H}_{2} \mathrm{O}^{* *} \rightarrow \mathrm{H}+\mathrm{O} .
$$

In reactions $(2.32),(2.35),(2.36)$ the excitation energy of a water molecule is different, hence we use various denotations.

Analyzing reactions $(2.32)-(2.36)$ at the end of the physico-chemical stage (up to the time $10^{-13} \div 10^{-12}$ sec from the beginning), one can see that there are hydrated electrons $\mathrm{e}_{\mathrm{aq}}^{-}$, ions $\mathrm{H}^{+}, \mathrm{OH}^{-}, \mathrm{H}_{3} \mathrm{O}^{+}\left(\mathrm{H}_{\mathrm{aq}}^{+}\right)$and radical products $\mathrm{O}, \mathrm{H}$ in aqueous solutions. Initially they are concentrated in tracks and characterized by a strongly inhomogeneous space distribution. Hence, those particles should diffuse in the bulk of a solution quickly reacting with each other and with the dissolved compounds. A high density of chemical radicals in tracks makes the reactions of their capturing by dissolved compounds ineffective in comparison with the recombination. As a result, the diffusive-recombination kinetics of chemical reactions appears. The main point consists in a competition between the mutual diffusion of chemically active particles and reactions occurring inside the tracks. At the chemical stage, the following reactions are possible in the tracks:

$$
\begin{aligned}
\mathrm{e}_{\mathrm{aq}}^{-}+\mathrm{H}_{2} \mathrm{O}^{+} & \rightarrow \mathrm{H}_{2} \mathrm{O}, \\
\mathrm{e}_{\mathrm{aq}}^{-}+\mathrm{OH} & \rightarrow \mathrm{OH}^{-}, \\
\mathrm{H}^{+}+\mathrm{H}_{2} \mathrm{O} & \rightarrow \mathrm{H}_{3} \mathrm{O}^{+}, \\
\mathrm{OH}^{-}+\mathrm{H}_{2} \mathrm{O}^{+} & \rightarrow \mathrm{H}_{2} \mathrm{O}+\mathrm{OH} \\
\mathrm{H}+\mathrm{H} & \rightarrow \mathrm{H}_{2}, \\
\mathrm{H}^{-}+\mathrm{H}^{+} & \rightarrow \mathrm{H}_{2}, \\
\mathrm{e}_{\mathrm{aq}}^{-}+\mathrm{H}_{2} \mathrm{O} & \rightarrow \mathrm{OH}^{-}+\mathrm{H}, \\
\mathrm{e}_{\mathrm{aq}}^{-}+\mathrm{H}_{2} \mathrm{O} & \rightarrow \mathrm{OH}^{-} \mathrm{H}^{-}, \\
\mathrm{e}_{\mathrm{aq}}^{-}+\mathrm{H} & \rightarrow \mathrm{H}^{-} \\
\mathrm{OH}+\mathrm{OH} & \rightarrow \mathrm{H}_{2} \mathrm{O}_{2}, \\
\mathrm{H}_{3} \mathrm{O}^{+}+\mathrm{e}_{\mathrm{aq}}^{-} & \rightarrow \mathrm{H}_{2} \mathrm{O}+\mathrm{H}^{-} \\
\mathrm{H}^{-}+\mathrm{H}_{3} \mathrm{O}^{+} & \rightarrow \mathrm{H}_{2} \mathrm{O}+\mathrm{H}_{2}, \\
\mathrm{H}^{-}+\mathrm{H}_{2} \mathrm{O}^{+} & \rightarrow \mathrm{H}_{2} \mathrm{O}+\mathrm{H}^{+} \\
\mathrm{H}^{-}+\mathrm{H}_{2} \mathrm{O} & \rightarrow \mathrm{OH}^{-}+\mathrm{H}_{2}, \\
\mathrm{e}_{\mathrm{aq}}^{-}+\mathrm{H}^{+} & \rightarrow \mathrm{H}^{-}
\end{aligned}
$$

The treatment of a hydrated electron in special literature is ambiguous. It often makes the understanding of some chemical transformations problematic. Sometimes $\mathrm{e}_{\mathrm{aq}}^{-}$denotes an $\mathrm{H}_{2} \mathrm{O}^{-}$ion [61]:

$$
\mathrm{e}_{\mathrm{aq}}^{-}+\mathrm{H} \rightarrow \mathrm{H}_{2}+\mathrm{OH}^{-} \text {. }
$$

At the same time $e_{a q}^{-}$is understood as an electron combined with water molecules. It does not participate in chemical transformations and has the transport property:

$$
\mathrm{e}_{\mathrm{aq}}^{-}+\mathrm{OH} \rightarrow \mathrm{OH}^{-} \text {. }
$$


In our paper we have tried to avoid this duality, as it leads to different values of the diffusion coefficients and kinetic properties of particles $\mathrm{H}_{2} \mathrm{O}^{-}$ and water molecules which transfer electron $\left(\mathrm{H}_{2} \mathrm{O}\right)_{n}^{-}$due to their different masses and dimensions. This should be applied to a hydrated proton as well: $\mathrm{H}^{+}$or $\mathrm{H}_{3} \mathrm{O}^{+}$. Any dualities here can be avoided by introducing a time limitation. It does mean that there appears a pure proton $\mathrm{H}^{+}$immediately after the ionized particle has passed $\left(10^{-14} \mathrm{sec}\right)$. The proton is hydrated at once into the hydroxonium ion $\mathrm{H}_{3} \mathrm{O}^{+}$, where it is connected with a water molecule by a persistent covalent donor-acceptor bond.

For a hydrated electron everything looks more complicated, because the connection mechanism of the electron to a water molecule is not definite. From the chemical point of view, it is problematical to interpret the hydrated electron as an $\mathrm{H}_{2} \mathrm{O}^{-}$ion. In our kinetic calculations, the hydrated electron means an electron surrounded by water molecules $\left(\mathrm{H}_{2} \mathrm{O}\right)_{n}^{-}$and it is denoted by $\mathrm{e}_{\mathrm{aq}}^{-}$in chemical transformations. These water molecules transfer electrons only and do not participate in any chemical transformations. In the case of an interaction between the hydrated electron and water molecules, the latter one should be written separately to avoid expressions like

$$
\mathrm{e}_{\mathrm{aq}}^{-}+\mathrm{e}_{\mathrm{aq}}^{-}+\rightarrow \mathrm{H}_{2}+2 \mathrm{OH}^{-} .
$$

An important result of the presented reactions is the creation of molecular hydrogen $\mathrm{H}_{2}$, hydrogen peroxide $\mathrm{H}_{2} \mathrm{O}_{2}$ and water $\mathrm{H}_{2} \mathrm{O}$.

Molecular products $\mathrm{H}_{2}, \mathrm{H}_{2} \mathrm{O}_{2}$ can be annihilated by the reactions

$$
\begin{aligned}
\mathrm{e}_{\mathrm{aq}}^{-}+\mathrm{H}_{2} \mathrm{O}_{2} & \rightarrow \mathrm{OH}+\mathrm{OH}^{-}, \\
\mathrm{H}+\mathrm{H}_{2} \mathrm{O}_{2} & \rightarrow \mathrm{OH}+\mathrm{H}_{2} \mathrm{O}, \\
\mathrm{OH}+\mathrm{H}_{2} \mathrm{O}_{2} & \rightarrow \mathrm{HO}_{2}+\mathrm{H}_{2} \mathrm{O}, \\
\mathrm{OH}+\mathrm{H}_{2} & \rightarrow \mathrm{H}+\mathrm{H}_{2} \mathrm{O}, \\
2 \mathrm{H}_{2} \mathrm{O}_{2} & \rightarrow 2 \mathrm{H}_{2} \mathrm{O}+\mathrm{O}_{2},
\end{aligned}
$$

while the radicals $\mathrm{OH}$ and $\mathrm{H}$ regenerate in water molecules

$$
\mathrm{H}+\mathrm{OH} \rightarrow \mathrm{H}_{2} \mathrm{O} .
$$

The radicals $\mathrm{HO}_{2}$ react fast to produce hydrogenium peroxide

$$
\mathrm{HO}_{2}+\mathrm{HO}_{2} \rightarrow \mathrm{H}_{2} \mathrm{O}_{2}+\mathrm{O}_{2} .
$$

Thus, as a result of the ionizing irradiation action on aqueous solutions, the particles with oxidation (OH radicals) and reduction (hydrated electrons and $\mathrm{H}$ atoms) properties are generated simultaneously.

Hence, at the end of the chemical stage $\left(10^{-12}-10^{-8} \mathrm{sec}\right)$ there are the following products of water radiolysis in the tracks: ions $\mathrm{e}_{\mathrm{aq}}^{-}, \mathrm{H}_{\mathrm{aq}}^{+}, \mathrm{OH}_{\mathrm{aq}}^{-}$, which do not recombine and $\mathrm{O}, \mathrm{H}, \mathrm{OH}, \mathrm{HO}_{2}, \mathrm{H}_{2}, \mathrm{H}_{2} \mathrm{O}_{2}, \mathrm{O}_{2}$ which interact actively with each other and with the substances dissolved in water, in particular, with uranyl ions $\mathrm{UO}_{2}^{2+}$, plutonyl ions $\mathrm{PuO}_{2}^{2+}$, ions $\mathrm{Cs}^{+}, \mathrm{Sr}^{2+}$ and other charged particles $-\mathrm{Fe}^{3+}, \mathrm{Na}^{+}, \mathrm{Cl}^{-}, \mathrm{NO}_{3}^{-}, \mathrm{SO}_{4}^{2-}, \mathrm{CO}_{3}^{2-}$.

In particular, the hydrogenium peroxide, created during radiolysis, participates in reactions with uranyl ions, forming uranium peroxide $\mathrm{UO}_{4}$

$$
\mathrm{UO}_{2}^{2+}+\mathrm{H}_{2} \mathrm{O}_{2} \rightarrow \mathrm{UO}_{4}+2 \mathrm{H}^{+} .
$$


The uranium peroxide (studtite) falls into the sediment in the form of $\mathrm{UO}_{4} \cdot 4 \mathrm{H}_{2} \mathrm{O}$ when its solvability limit is exceeded. It can decay thermally according to the reactions

$$
\begin{aligned}
\mathrm{UO}_{4}+2 \mathrm{H}^{+} & \rightarrow \mathrm{UO}_{2}^{2+}+\mathrm{H}_{2} \mathrm{O}_{2}, \\
\mathrm{UO}_{4} & \rightarrow \mathrm{UO}_{3}+\frac{1}{2} \mathrm{O}_{2}, \\
\mathrm{UO}_{3}+2 \mathrm{H}^{+} & \rightarrow \mathrm{UO}_{2}^{2+}+\mathrm{H}_{2} \mathrm{O} .
\end{aligned}
$$

It is obvious that uranium mineral creations $\mathrm{UO}_{3} \cdot 2 \mathrm{H}_{2} \mathrm{O}$ and $\mathrm{UO}_{4} \cdot 4 \mathrm{H}_{2} \mathrm{O}$ appear on the surface of FCM (see the reactions presented above) when hydrargyrum peroxide and aqueous solutions are available.

For the calculation of the radiolysis products yield and for its comparison with the experimental data, the equations of chemical kinetics are used [53-58], which could be obtained on the basis of nonequilibrium statistical thermodynamics [59]. Not taking into account the processes dealing with energy and momentum fluctuations and considering the chemical processes in aqueous solutions to have a reaction-diffusion character, one can write down an equation for the reagents concentration in the general form:

$$
\frac{\partial}{\partial t} \rho_{a}(\boldsymbol{r} ; t)=G_{a} J+\sum_{m, n} K_{m n} \rho_{m} \rho_{n}-\sum_{b} K_{a b} \rho_{a} \rho_{b}+F_{a}
$$

$\rho_{a}, \rho_{m}, \rho_{n}, \rho_{b}$ denote the concentrations of $a, m, n, b$ - species particles; $K_{m n}$ and $K_{a b}$ denote the rate constants of the creation and annihilation of $a$-specie particles in the reactions between $m, n, b$-species particles, correspondingly, $\sum_{m, n}$ means the summation over all the reactions leading to the creation of $a$-species particles, $\sum_{b}$ is the sum of reactions when $a$-species particles disappear, $F_{a}$ describes the $a$-particles transfer due to molecular diffusion and water flow with velocity $\boldsymbol{v}(\boldsymbol{r} ; t)$ :

$$
F_{a}=-\operatorname{div}\left(\boldsymbol{v}(\boldsymbol{r} ; t) \rho_{a}\right)+\operatorname{div}\left(D_{a} \operatorname{grad} \rho_{a}\right) .
$$

$D_{a}$ means the diffusion coefficient of $a$-particles, $G_{a}$ denotes the yield of $a$-species particles during radiolysis. Units of measuring $G$ are particles/ $100 \mathrm{eV}, \rho-\mathrm{mol} / 10^{-3} \mathrm{~m}^{3}$, radiation capacity $R C$ is measured in $\mathrm{eV}$ per (litre-sec).

$$
J=R C /\left(100 N_{\mathrm{A}}\right) .
$$

Initial yield $G_{a}$ during ionization (before reactions inside tracks) is determined by formula [58]:

$$
G_{a}=\left.100 N_{A} \frac{\mathrm{d} \rho_{a}}{\mathrm{~d} D_{a}}\right|_{D_{a}=D_{a}^{o}}
$$

or

$$
G_{a}=100 N_{\mathrm{A}} \frac{\rho_{a}}{D_{a}} .
$$

where $N_{\mathrm{A}}$ is the Avogadro number.

Hence, the change in the concentration of particles interacting according to (2.32)-(2.54) will be investigated on the basis of kinetic equations (2.55). 
In every equation for molecular products $\mathrm{H}_{2} \mathrm{O}, \mathrm{H}_{2}, \mathrm{H}_{2} \mathrm{O}_{2}$ the concentrations of ions and other particles of solution are involved. So the reaction-diffusion equations ought to be written for all the particles involved in the radiolysis process. Besides, one has to take into consideration the reactions at the chemical stage.

The system of equations (2.55) is nonlinear and can only be solved numerically. However, sometimes it might be simplified, for example, in the case of weakly nonequilibrium radiolysis processes. Experimental data show that the rate constants values for reactions between chemical radicals, and between radicals and other particles are much larger than other rate constants. That is why the concentration of radicals is much smaller than the concentration of stable products of radiolysis, thus one can suppose the establishment of a steady state for radicals after ionization, taking the approximation of stationary concentrations:

$$
\frac{\partial}{\partial t} \rho_{R}(\boldsymbol{r} ; t)=0
$$

( $R$ is a denotation for a radical). Such a condition is not valid for stable products of radiolysis. So introducing the denotation

$$
\rho_{R}(\boldsymbol{r} ; t)=\left\{\rho_{\mathrm{H}}, \rho_{\mathrm{OH}}, \rho_{\mathrm{H}^{+}}, \rho_{\mathrm{OH}^{-}}, \rho_{\mathrm{H}_{2} \mathrm{O}^{+}}, \rho_{\mathrm{e}_{\mathrm{aq}}^{-}}, \rho_{\mathrm{H}_{3} \mathrm{O}^{+}}, \rho_{\mathrm{H}^{-}}\right\}
$$

for chemical radicals, and the denotation

$$
\rho_{M}(\boldsymbol{r} ; t)=\left\{\rho_{\mathrm{H}_{2} \mathrm{O}}, \rho_{\mathrm{H}_{2}}, \rho_{\mathrm{H}_{2} \mathrm{O}_{2}}, \rho_{\mathrm{O}_{2}}\right\}
$$

for stable molecular products of radiolysis, one can formally represent the system of equations (2.55) as a system for $\rho_{M}(\boldsymbol{r}, t)$ and $\rho_{R}(\boldsymbol{r}, t)$ :

$$
\begin{aligned}
\frac{\partial}{\partial t} \rho_{M}(\boldsymbol{r} ; t) & =G_{M} J+\sum_{m, n} K_{m n} \rho_{m} \rho_{n}-\sum_{l} K_{l M} \rho_{l} \rho_{M}+F_{M} \\
0 & =G_{R} J+\sum_{m, n} K_{m n} \rho_{m} \rho_{n}-\sum_{l} K_{l R} \rho_{l} \rho_{R}+F_{R}
\end{aligned}
$$

with the initial conditions $\rho_{M}(t=0)=\rho_{M}^{0}$ and $\rho_{R}(t=0)=0$.

If the system of equations (2.70) could be solved with respect to radicals concentrations, then, substituting this solution into (2.69), we obtain a closed chain of equations for the concentrations of molecular products.

For the calculation of rate constants in aqueous solutions, one can use the formulae which connect $K_{a b}$ with the diffusion coefficients of each component and with the structure of the solution itself. In particular, for rapid reactions one can apply the Smoluchowsky expression for rate constants:

$$
K_{a b}=4 \pi\left(D_{a}+D_{b}\right) R_{a b},
$$

where $D_{a}, D_{b}$ are the diffusion coefficients for reagents $a$ and $b$. The value $R_{a b}$ is called a collision radius. It is approximately equal to the sum of the radii of $a-$ and $b$-molecules. On the basis of a hydrodynamic level of the description of chemical reactions in solutions $[59,60]$ one can obtain the expressions for the rate constants of chemical reactions:

$$
K_{a b}(t)=\int \mathrm{d} \boldsymbol{r}_{a b} k^{0}\left(\boldsymbol{r}_{a b}\right) g_{a b}\left(\boldsymbol{r}_{a b} ; t\right),
$$


where $k^{0}\left(\boldsymbol{r}_{a b}\right)$ denotes the proper reactional ability, $g_{a b}\left(\boldsymbol{r}_{a b} ; t\right)$ is the nonequilibrium radial distribution function of particles in solutions. In a steady state, $g_{a b}\left(\boldsymbol{r}_{a b}\right)$ means the equilibrium radial distribution function and the rate constant $K_{a b}$ does not depend on time:

$$
K_{a b}=4 \pi \int \mathrm{d} r_{a b} k^{0}\left(r_{a b}\right) g_{a b}\left(r_{a b}\right) .
$$

The proper reacting ability $k^{0}\left(r_{a b}\right)$ of molecules depends on the mechanism of elementary reactions and, in principle, can be calculated either by classical or quantum mechanics methods. The simplest form has the Smoluchowsky proper reacting ability constant

$$
k^{0}\left(r_{a b}\right)=k^{0} \delta\left(r_{a b}-R_{a b}\right) / 4 \pi r_{a b}^{2},
$$

then

$$
K_{a b}=k^{0} g_{a b}\left(R_{a b}\right),
$$

where $k^{0}=4 \pi R_{a b}^{2}(8 / \beta \pi \mu)^{1 / 2}, \mu=m_{a} m_{b} /\left(m_{a}+m_{b}\right)$ is the reduced mass of particles $a$ and $b$. So the problem of the calculation of rate constants for chemical reactions is reduced to the evaluation of diffusion coefficients and structural distribution functions of reagents.

In view of the statistical theory of interacting particles, the aqueous solutions of radioactive elements, in which radiolysis reactions take place, can be considered as a model electron-ion-atomic-molecular (plasma-molecular) system. The peculiarity of such a system consists in a long-range character of Coulomb and dipole forces between ions and electrons $\left(\mathrm{H}^{+}, \mathrm{OH}^{-}\right.$, $\left.\mathrm{e}_{\mathrm{aq}}^{-}, \mathrm{H}^{-}, \mathrm{H}_{3} \mathrm{O}^{+}\right)$, as well as between molecules $\left(\mathrm{H}_{2}, \mathrm{H}_{2} \mathrm{O}, \mathrm{H}_{2} \mathrm{O}_{2}\right)$. Besides, there exist hydrogen atoms $\mathrm{H}$ and hydroxyl $\mathrm{OH}$ groups in the system. They actively participate in transport processes and chemical reactions in the solution. The multiple dynamical processes, which are marked by both shortrange and long-range correlations, lead to the phenomena of solvatation and complex formation in solutions. The investigation of structure, thermodynamical and kinetic properties of such plasma-molecular solutions is actual. Besides, the nonequilibrium distribution functions $g_{A B}(\boldsymbol{r} ; t)$, which are connected with chemical reactions constants (2.64), have not yet been studied appropriately. A considerable achievement in the investigation of plasma-molecular systems was made in [62]. On the other hand, the constants of quasiequilibrium states of chemical reactions could be defined via pair distribution functions (2.65) of electrons, ions, atoms and molecules. Methods of the investigation of equilibrium distribution functions of particles of electrolytes (in the ion and ion-molecular approaches) are described in $[62,63]$.

For qualitative estimations, the rate constants can be calculated on the basis of an ion-dipole model of aqueous solutions [18]. Within the framework of this model the particles interact as hard spheres on short ranges with the equilibrium distribution $g_{a b}\left(\sigma_{a b}\right)\left(\sigma_{a b}=\frac{1}{2}\left(\sigma_{a}+\sigma_{b}\right)\right.$, where at $\sigma_{a}, \sigma_{b}$ are hard spheres diameters), whereas at large distances they interact through the ion, ion-dipole and dipole-dipole potentials which are characterized by electrostatic screening. For an ion-dipole system the equilibrium pair distribution function can be presented in the approximation of the second virial coefficient

$$
g_{a b}(r)=g_{a b}\left(\sigma_{a b}\right) \exp \left\{G_{a b}(r)\right\},
$$

where $\mathrm{G}_{a b}$ is the screened potential of electrostatic interactions. For an ion-dipole system the screened potentials of electrostatic interactions can 
be obtained from $[62,63]$ :

$$
\begin{gathered}
G_{a b}(r)=-\beta \frac{Z_{a} Z_{b} e^{2}}{\varepsilon r} \exp \left\{-\frac{\kappa}{\sqrt{\varepsilon}} r\right\} \\
G_{a s}(r)=\beta Z_{a} e d_{s} \frac{1}{\varepsilon r}\left(\frac{1}{r}+\frac{\kappa}{\sqrt{\varepsilon}}\right) \exp \left\{-\frac{\kappa}{\sqrt{\varepsilon}} r\right\} \cos \theta_{s}, \\
G_{r s}(r)=\beta d_{s} d_{r} \frac{1}{\varepsilon r}\left\{\left(\frac{2}{r^{2}}+\frac{2 \kappa}{\sqrt{\varepsilon} r}+\frac{\kappa}{\sqrt{\varepsilon}}\right) \cos \theta_{s} \cos \theta_{r}-\right. \\
\left.-\frac{1}{r}\left(\frac{1}{r}+\frac{\kappa}{\sqrt{\varepsilon}}\right) \sin \theta_{s} \sin \theta_{r} \cos \left(\varphi_{s}-\varphi_{r}\right)\right\} \exp \left\{-\frac{\kappa}{\sqrt{\varepsilon}} r\right\},
\end{gathered}
$$

$\kappa=\left(4 \pi \beta \sum_{a} \frac{N_{a}}{V} Z_{a}^{2} e^{2}\right)^{1 / 2}$ means the value which is inverse to the Debye screening radius, $\varepsilon$ denotes dielectric penetreability, $\beta=1 / k_{\mathrm{B}} T, k_{\mathrm{B}}$ is the Boltzmann constant, $T$ is the temperature, $Z_{a} e$ denotes the $a$-kind ion charge, $d_{s}$ is the value of dipole moment for molecules, $Q_{s}$ and $\varphi_{s}$ are orientation angles. In particular, a hydrated electron can be considered as an ion with the charge $Z_{\mathrm{e}_{\mathrm{aq}}^{-}}=-1$ and the effective radius $\sigma_{\mathrm{e}_{\mathrm{aq}}^{-}}=2.5 \div 3.0 \AA$ and with the diffusion coefficient $4.9 \div 0.25 \cdot 10^{-5} \mathrm{~cm}^{2} / \mathrm{sec}$.

The calculation of radiolysis rate constants on the basis of formulae (2.32)-(2.54) for a dipole model of water will be carried out in our further papers. Investigation of the solutions diffusion coefficients is important from the point of view of the kinetic calculation of chemical reactions (2.55). One approach of an approximate calculation of transport coefficients for ions $\mathrm{UO}_{2}^{2+}, \mathrm{Sr}^{2+}, \mathrm{Cs}^{+}$in aqueous solutions and FCM is presented below.

\subsection{Coefficients of mutual diffusion and viscosities for ions $\mathrm{UO}_{2}^{2+}, \mathrm{PuO}_{2}^{2+}$ $\mathrm{Sr}^{2+}, \mathrm{Cs}^{+}$in aqueous solutions of radioactive elements and in FCM}

An important stage of the investigation of nuclear physico-chemical processes in the system "FCM - aqueous solutions" is, undoubtedly, the study of diffusion and thermal diffusion processes and viscosity of radioactive elements $\left(\mathrm{UO}_{2}^{2+}, \mathrm{PuO}_{2}^{2+}, \mathrm{Sr}^{2+}, \mathrm{Cs}^{+}\right)$both in $\mathrm{FCM}$ and in aqueous solutions. Specifically, the calculation of diffusion coefficients for ions, radicals and molecules in aqueous solutions is important for studying chemical reactions of hydrolysis which were considered in subsections $2.1,2.3$. On the other hand, the investigation of diffusion coefficients for ions $\mathrm{UO}_{2}^{2+}, \mathrm{PuO}_{2}^{2+}$ in glassy FCM is important from the point of view of nuclear transformations and calculations of neutron density flow spectra. The problem of the calculation of such transport coefficients as diffusion and viscosity for ions $\mathrm{UO}_{2}^{2+}$, $\mathrm{PuO}_{2}^{2+}, \mathrm{Sr}^{2+}, \mathrm{Cs}^{+}$in glassy-like FCM and in aqueous solutions can be solved on the basis of the generalized Enskog-Landau kinetic equation for a multicomponent system of charged hard spheres [65-68]. We will use a model where the silicium matrix is treated as an environment with the fixed dielectric constant $\varepsilon=1 \div 15$ and in which ions of $\mathrm{UO}_{2}^{2+}, \mathrm{PuO}_{2}^{2+}, \mathrm{Sr}^{2+}, \mathrm{Cs}^{+}$run in an effective compensating field correspondingly to the electroneutrality condition. Similarly, aqueous solutions will be treated on the basis of an ion approach, when the solvent is modelled by a molecular subsystem with the dielectric constant $\varepsilon_{\mathrm{w}}=81$ and ions $\mathrm{UO}_{2}^{2+}, \mathrm{PuO}_{2}^{2+}, \mathrm{Sr}^{2+}, \mathrm{Cs}^{+}$run inside it in an effective compensating field correspondingly to the electroneutrality condition as well. 
To calculate the viscosity and diffusion coefficients we use the results of our previous works $[67,68]$. It will be, of course, rather an approximate description, as formulae $[67,68]$ were obtained for a two-component system of charged hard spheres. They limit our consideration to two systems, namely " $\mathrm{UO}_{2}^{2+}-\mathrm{PuO}_{2}^{2+"}$ and " $\mathrm{Cs}^{+}-\mathrm{Sr}^{2+}$ ". The results of the calculation at different concentrations are shown in figures 2 and 3.

The mutual diffusion $D^{\alpha \beta}$ and shear viscosity $\eta$ coefficients read $[67,68]$

$$
\begin{gathered}
D^{\alpha \beta}=\frac{3}{8 n} \sqrt{\frac{\pi k_{\mathrm{B}} T}{2 m^{*}}}\left[g_{2}^{\alpha \beta}\left(\sigma_{\alpha \beta} \mid n, \beta\right) \sigma_{\alpha \beta}^{2}+\frac{\pi^{2}}{8}\left(\frac{Z_{\alpha} Z_{\beta} e^{2}}{k_{\mathrm{B}} T}\right)^{2} \ln \frac{D}{\sigma_{\alpha \beta}}\right]^{-1}, \quad(2.77) \\
\eta=\frac{3}{5} \kappa+\frac{1}{2} \sum_{\alpha=1}^{M} n_{\alpha} k_{\mathrm{B}} T\left[1+\frac{2 \pi}{15} \sum_{\beta=1}^{M} n_{\beta} \sigma_{\alpha \beta}^{3} g_{2}^{\alpha \beta}\left(\sigma_{\alpha \beta} \mid n, \beta\right)\left[1+\frac{m_{\alpha} B_{0}^{\beta}}{m_{\beta} B_{0}^{\alpha}}\right]\right] B_{0}^{\alpha} .
\end{gathered}
$$

The following conventional designations are used in those formulae:

$\beta \quad$ inverse local temperature analogue;

$D \quad$ screening radius borrowed from [69];

$g_{2}^{\alpha \beta}$ two-particle correlation function borrowed from [70];

$\kappa \quad$ bulk viscosity borrowed from $[67,68]$;

$m^{*} \quad$ reduced mass;

$m_{\alpha} \quad$ partial masses of particles;

$n$ total density of particles number:

$n_{\alpha} \quad$ partial densities of particles numbers;

$\sigma_{\alpha \beta}$ averaged value of hard spheres diameter;

$Z_{\alpha}$ values of ions charges in the positron charge units: $Z_{\alpha} \in \mathbb{Z}$.

The coefficients $B_{0}^{\alpha}$ appear at the expansion on Sonine-Laguerre polynomials and are calculated via the so-called $\Omega$-integrals [71]. For the system under consideration their evident structures were found in papers $[67,68]$.

\section{Conclusions}

In this paper an analysis of the interaction of FCM with water, as well as an investigation of radiolysis of aqueous solutions of radioactive elements in the "Shelter" object has been carried out. Considering the interaction between the radiolysis products and FCM we have shown that the way of the formation of uranium peroxide tetrahydrate $\mathrm{UO}_{4} \cdot 4 \mathrm{H}_{2} \mathrm{O}$ (its availability was confirmed in the "Shelter" object experimentally) is in accordance with the reaction

$$
\mathrm{UO}_{2}^{2+}+\mathrm{H}_{2} \mathrm{O}_{2} \stackrel{\mathrm{H}_{2} \mathrm{O}}{\longrightarrow} \mathrm{UO}_{4} \cdot 4 \mathrm{H}_{2} \mathrm{O}+2 \mathrm{H}^{+} \text {, }
$$

whereas the uranyl ion $\mathrm{UO}_{2}$ in its turn is obtained from FCM after the reaction

$$
\mathrm{UO}_{2}+2 \mathrm{OH} \rightarrow \mathrm{UO}_{2}^{2+}+2 \mathrm{OH}^{-} .
$$

In both the reactions the products of water radiolysis take part (hydrogen peroxide and radicals $\mathrm{OH}$, whose concentration is large at $\mathrm{pH}=9 \div 12$ in aqueous solutions, are typical of the "Shelter" object). The same refers to the formation of other uranium minerals found on the FCM surface. It obviously follows that one needs a profound analysis of radiolysis kinetics, the calculation of coefficients for the reaction rates of the formation of such 

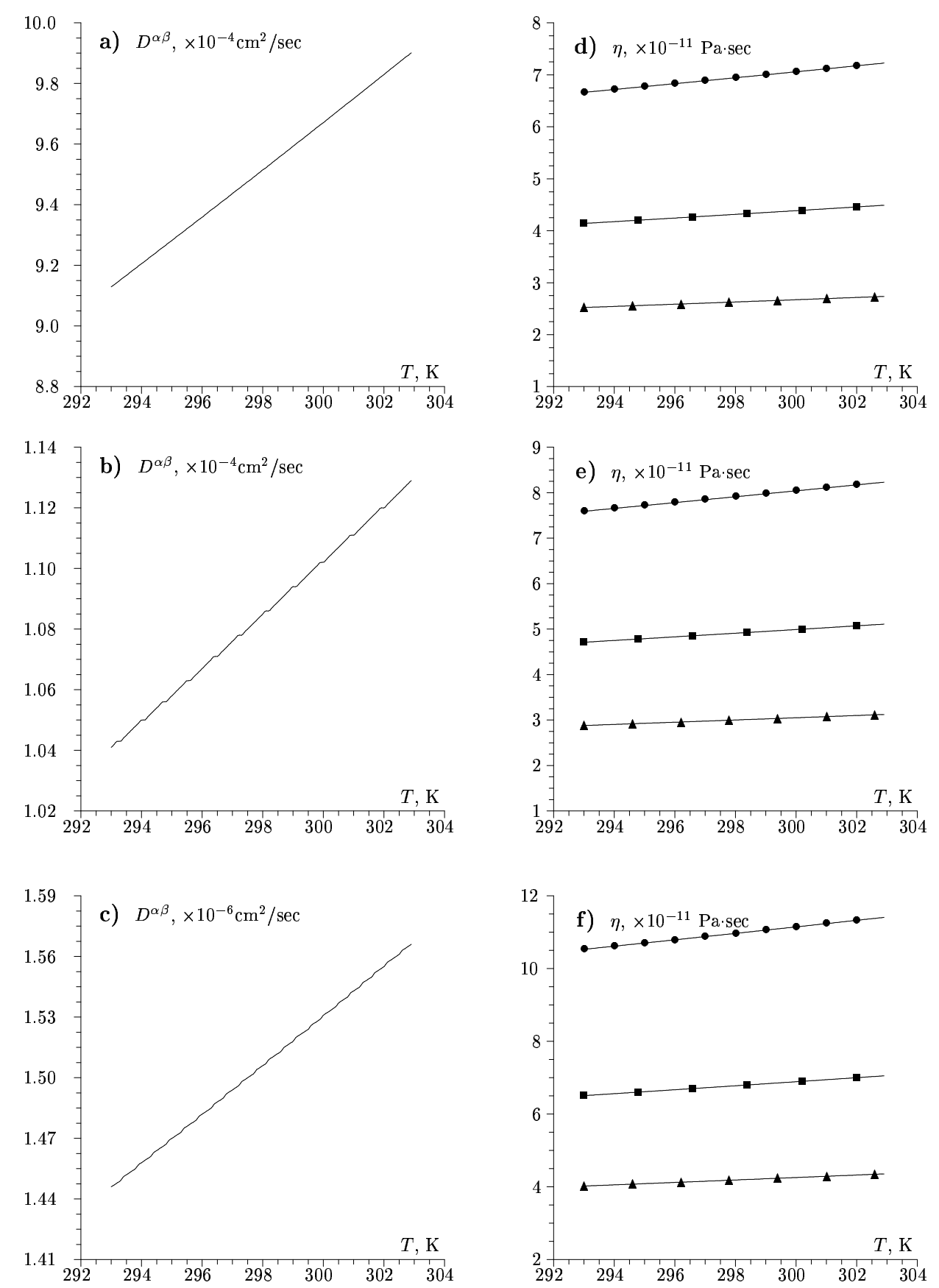

Figure 2. Mutual diffusion $D^{\alpha \beta}$ and shear viscosity $\eta$ transport coefficients temperature dependences for the system of ions $\mathrm{Cs}^{+}, \mathrm{Sr}^{2+}$ in aqueous solution at differnt concentrations: a), d) $-1 \mathrm{mg} / \mathrm{l}$; b), e) $-10 \mathrm{mg} / \mathrm{l}$; c), f) - 1 $\mathrm{g} / \mathrm{l}$. The legend for viscosity reads: - - total value, $-\mathrm{Cs}^{+}, \mathbf{\Lambda}-\mathrm{Sr}^{2+}$. 

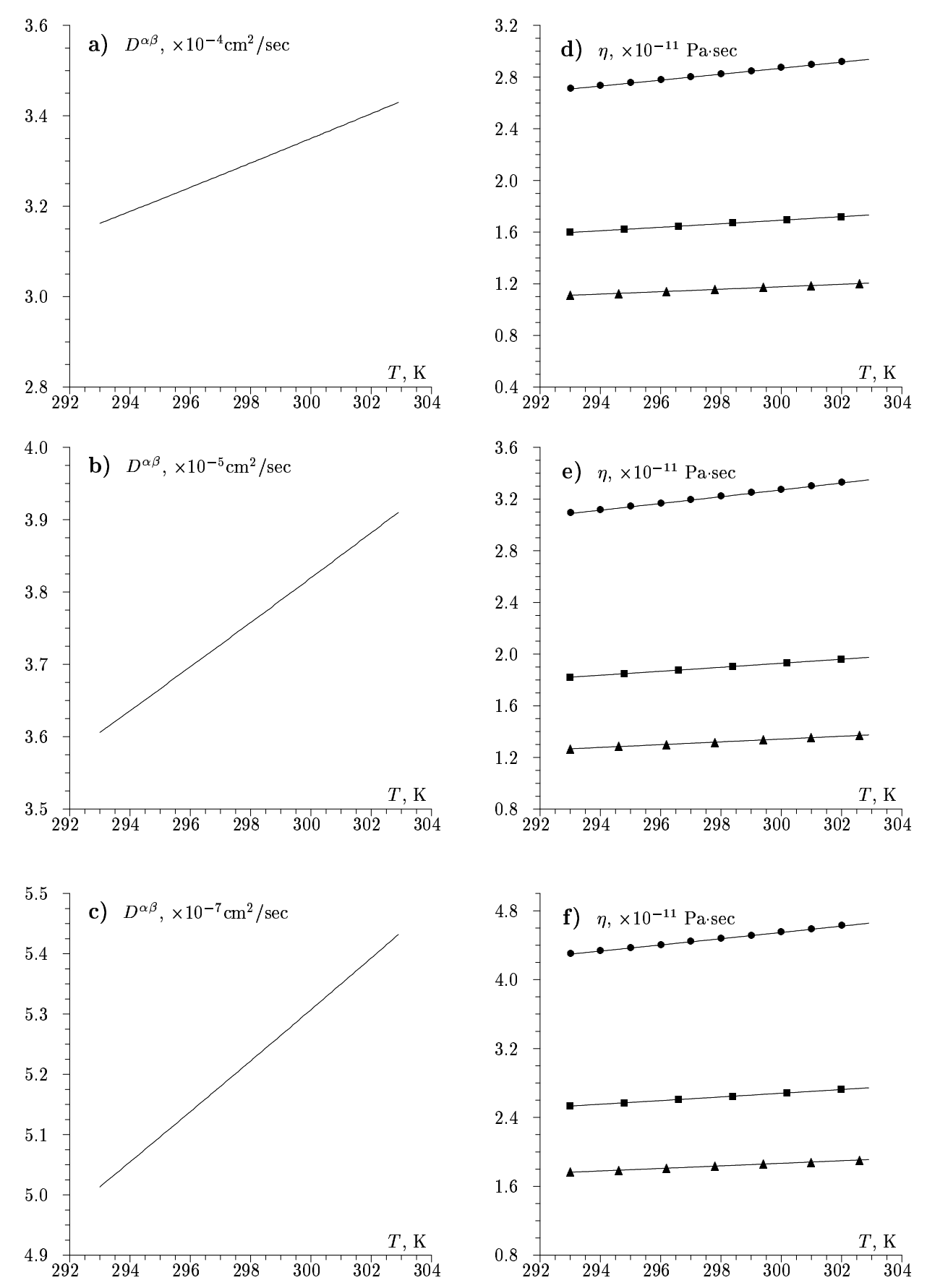

Figure 3. The temperature dependences of mutual diffusion $D^{\alpha \beta}$ and shear viscosity $\eta$ transport coefficients for the system of ions $\mathrm{UO}_{2}^{2+}, \mathrm{PuO}_{2}^{2+}$ at differnt concentrations: a), d) - $1 \mathrm{mg} / \mathrm{l}$; b), e) - $10 \mathrm{mg} / \mathrm{l}$; c), f) - $1 \mathrm{~g} / \mathrm{l}$. The legend for viscosity reads: $\bullet-$ total value, $-\mathrm{PuO}_{2}^{2+}$, $\Delta-\mathrm{UO}_{2}^{2+}$. 
products as hydrogen peroxide and others. At the same time, there is a problem of the formation of atomic and molecular hydrogen taking an active part in the glassy FCM disintegration.

Except for the problem of radiolysis, we have discussed the mechanisms of the glassy $\mathrm{FCM}$ disintegration at the interaction with $\mathrm{pH}=9 \div 11$ aqueous solutions. We have computed the structural distribution functions for ions $\mathrm{UO}_{2}^{2+}, \mathrm{Sr}^{2+}, \mathrm{Cs}^{+}$in these systems, which enables one to calculate the rates for the corresponding chemical reactions and their dynamics in further research. The mutual diffusion and viscosity coefficients are studied for ions $\mathrm{Cs}^{+}, \mathrm{Sr}^{2+}, \mathrm{PuO}_{2}^{2+}, \mathrm{UO}_{2}^{2+}$ in aqueous solutions depending on concentration and temperature. The evaluations are qualitative, since the solvent molecules have not been treated microscopically. In view of the transport prediction in such systems, it is important to investigate the coefficients of diffusion, thermodiffusion and thermal conductivity for ions $\mathrm{Cs}^{+}, \mathrm{Sr}^{2+}$, $\mathrm{Pu} \mathrm{O}_{2}^{2+}, \mathrm{UO}_{2}^{2+}$. We intend to fulfil it in our further papers.

Nuclear, physical and chemical processes occurring at the FCM interaction with aqueous solutions in the "Shelter" object, are tightly related. Our research on radiolysis, hydration, chemical reactions with the participation of $\mathrm{UO}_{2}^{2+}, \mathrm{Pu} \mathrm{O}_{2}^{2+}, \mathrm{Cs}^{+}, \mathrm{Sr}^{2+}$, their structural distribution functions and transport coefficients is only an element of the physical and mathematical model for the behaviour of FCM in the "Shelter" object. The model is designated to predict nuclear, physical and chemical processes and provide the object stabilization, gradual extraction of the nuclear fuel and its further processing.

The problem of water in the "Sarcophagus" should be considered in view of nuclear material extraction from the object. Water is an important factor for FCM disintegration and the egress of radioactive elements into the basins. The controlled pumping out of water into assigned containers will enable one to gradually remove the nuclear fuel present in the dust (sprinkling the dust) and glassy states (intensive disruption of glassy lavas occur). The pumped radioactive water can be stored in the containers to prepare it for further processing at a radiochemical plant.

\section{Acknowledgements}

This work has been supported by the International Association for the Promotion of Cooperation between the NIS countries and European Community (grant INTAS-Ukraine-95-0133).

\section{References}

[1] Yukhnovskii I.R., Tokarchuk M.V. The problems of the 4 th powerblock of Chornobyl NPS I. Review. Lviv, 1995. Preprint ICMP-95-3U, 40 p.

[2] Yukhnovskii I.R., Tokarchuk M.V., Omelyan I.P., Zhelem R.I. Statistical theory of diffusion of radionuclides in the ground and underground water I. Statistical model. Lviv, 1994. Preprint ICMP-94-7E, 20 p.

[3] Technical substantiation of nuclear safety of the object "Shelter". Belyajev S.T., Borovoi A.A., Volkov K.G. et al. Moscow, Chornobyl complex expedition at Kurchatov Inst. Atom. Energy, 1990, 160 p. (in Russian).

[4] Accident on Chernobyl Atomic Power Station and its consequences. Information prepared for MAGATE experts conference. (25-29 August, 1986). Moscow, State Commitee for Usage of Atomic Energy, USSR, 1986.

[5] Abagyan A.A., Amanov V.G., Guskov A.K. Information about accident on Chernobyl Atomic Power Station and its consequences prepared for MAGATE. // Atomic Energy, 1986, vol. 61, No 3, p. 301-320 (in Russian). 
[6] Final report about conference for consideration of causes and consequences of Chernobyl disaster. Wien. IAEA. 75-INSAG-1, 1988.

[7] Asmolov V.G., Borovoi A.A. et al. Disaster on Chernobyl Atomic Power Station. // Atomic Energy, 1988, vol. 64, No 1, p. 3-23 (in Russian).

[8] Chernobyl. Five difficult years. Collection of materials. Moscow, 1992 (in Russian).

[9] Selected papers of International Conference "Nuclear disasters and future of energetics". Chernobyl lessons. Moscow. Atomic energy, 1992.

[10] Main scientifical and technical results obtained at the department for nuclear and radioactive safety in 1994 . Chornobyl, 1994, 137 p. (in Russian).

[11] Pazukhin E.M. Lava-shaped fuel containing mediums at the 4 th block of Chornobyl Atomic Power Station: Topography, physical and chemical properties, version as to formation. // Radiohimiya, 1994, vol. 34, No 2, p. 97-142 (in Russian).

[12] Anderson E.B., Borovoi A.A., Burakov B.E., Krinitsyn A.P., Pazukhin E.M., Checherov K.P. Technogeneous products of interaction of fuel and constructing materials, obtained after Chornobyl disaster. // Radiohimiya, 1992, No 5, c. 144-155 (in Russian).

[13] Kiselyov A.N., Nenaglyadov A.Yu., Surin A.I. et al. Experimental researches in lava-shaped fuel containing mediums at the 4 th block of Chornobyl Atomic Power Station. Moscow, 1992, 120 p. Preprint of Atomic Power Institute $5533 / 3$ (in Russian).

[14] Kiselyov A.N., Checherov K.P. Lava-like fuel-containing masses on 4 th unit of Chernobyl Atomic Power Station. Report on International conference "Shelter" safety - 94", March 14-18, 1994.

[15] Kiselyov A.N., Surin A.I., Checherov K.P. Results of supplementary investigations on accumulations of lava-shaped fuel containing mediums at the 4 th block of Chornobyl Atomic Power Station. Moscow, 1994, 59 p. Preprint of Atomic Power Institute - 5783/3 (in Russian).

[16] Kiselyov A.N. How much fuel is in lava-like fuel containing mass in 4 th unit of Chernobyl Atomic Power Station? // Atomic Energy, 1995, vol. 78, No 4, p. 256-259 (in Russian).

[17] Report on scientific and technical work "Nuclear safety of the object "Shelter" on the basis of investigations of break down processes dynamics". Inventory No 1515, Minsk, 1991 (in Russian).

[18] Calculation and experimental investigations of neutron fields characteristics in the places of accumulation of lava-shaped fuel containing masses inside premises 304/2 and 305/2 of the object "Shelter". Report, Minsk, 1994, 77 p (in Russian).

[19] Anderson E.B., Burakov B.E., Pazukhin E.M. Secondary mutation of fuel containing masses of Chornobyl atomic power plant 4 th reactor. // Radiohimiya, 1992, No 5, p. 135-138 (in Russian).

[20] Development of method and estimation of the contribution of $(\alpha, n)$ reactions in neutron intensity generated in lava-like fuel containing masses in premises $305 / 2$ and 304/2 of the object "Shelter". Report, Minks, 1994, 77 p (in Russian).

[21] An estimate of $(\alpha, n)$ reaction contribution into neutron intensivity, generated inside fuel containing materials in premises 305/2 of the object "Shelter". Technical certificate. Minsk, 1995, Sci. Ind. Center "Kamerton", p. 1-6 (in Russian).

[22] Statement on radionuclide content determination for water probes taken from premises of the object "Shelter" 23.02.1995. Chornobyl, 1995, 2 p. (in Russian).

[23] Results of the investigation of water accumulations in the premises of the object "Shelter". Suggestion of countersteps. Report, Chornobyl, 1993, 16 p. (in Russian).

[24] Working through methods for radiochemical extraction of uranium from fuel containing samples and carrying out mass-spectroelectric measurements of 
uranium's isotopic content with the purpose of the straight forward burn-up determination for the nuclear fuel inside a fuel containing medium. Report, Inventory No 11.07/118 since 12.03.1991. Kurchatov Institute of Atomic Power, 1991, 21 p (in Russian).

[25] Year report of the department for working through methods and analysis systems for radioactive technologies. International scientifical and technical center of National Ukrainian Academy of Sciences "Shelter", 1994, 44 p. (in Russian).

[26] Yukhnovskii I.R., Kobryn A.E., Tokarevskii V.V., Tokarchuk M.V. Problems on interaction between water and fuel containing masses inside the object "Shelter" of Chornobyl Nuclear Power Plant. Preprint ICMP-9619U, 24 p (in Ukrainian).

[27] Yukhnovskii I.R., Kobryn A.E., Tokarevskii V.V., Tokarchuk M.V. Problems on interaction between water and fuel containing masses inside the object "Shelter" of Chornobyl Nuclear Power Plant. // J. Phys. Studies, 1997, vol. 1, No 2, p. 169-180 (in Ukrainian).

[28] Kluchnikov A.A. The results of scientific-research and experimental-construction measures, which were held on the object "Shelter" to reach its stabilization. Report on Second International scientific and technical conference, devoted to 10 th annyversary of completion of the building of the object "Shelter". Chornobyl, 1996, 21 p (in Russian).

[29] Yukhnovskii I.R., Kobryn A.E., Muzychuk A.O., Tokarchuk M.V. Problems of description of nuclear, physical and chemical processes in nuclear magma inside the object "Shelter" III. Statistical description of transfer processes in nuclear magma. Lviv, 1996. Preprint ICMP-96-07U, 8 p (in Ukrainian).

[30] Report of the Department for Theoretical Problems of Physico-Chemical Processes in Matter containing Radioactive Elements of the Branch of Radioactive Technologies of Materials of Interbranch Scientific and Technical Center "Shelter" of the Ukrainian National Academy of Sciences in 1995. Chornobyl, 1995, $33 \mathrm{p}$ (in Ukrainian).

[31] Yukhnovskii I.R., Ivankiv O.L., Ignatyuk V.V., Dmytriv G.S., Tokarchuk M.V. Problems of description of nuclear, physical and chemical processes in nuclear magma inside the object "Shelter" I. Radiolysis in "nuclear magma - water" system. Lviv, 1996. Preprint ICMP-96-05U, 16 p (in Ukrainian).

[32] Yukhnovskii I.R., Omelyan I.P., Sovyak E.M., Zhelem R.I., Tokarchuk M.V. Problems of description of nuclear, physical and chemical processes in nuclear magma inside the object "Shelter" II. Description of diffusion processes in "nuclear magma - water" system. Lviv, 1996. Preprint ICMP-96-06U, 19 p (in Ukrainian).

[33] Babenko V.A., Vertsimakha O.Ya., Enkovskii L.L., Pavlovich V.N., Romanow V.N. Investigation of multiplicating properties of fuel containing masses of the 4 th block at Chornobyl Atomic Power Plant. Kiev, 1997. Preprint of KINR-97-1, 29 p. (in Russian).

[34] Yukhnovskii I.R., Tokarchuk M.V., Omelyan I.P., Sovyak E.M., Zhelem R.I. On the description of structural distribution and diffusion of radioactive elements in the system "glassy nuclear magma - water". // Cond. Matt. Phys., 1997, No 9, p.153-166.

[35] Ledenev A.I., Ovcharov P.A., Mishunina I.B., Antropov V.M. Results of complex studies in radiation state of temporary areas for radioactive waste localization in the Chernobyl estrangement zone. // Problems of Chernobyl exclusion zone, 1995, No 2, p. 46-51 (in Russian).

[36] Mishunina I.B., Ledenev A.I., Khvesik O.V. Estimation of safety of radionuclide localization in temporary areas for radioactive waste localization in the Chernobyl estrangement zone. // Problems of Chernobyl exclusion zone, 1995, No 2, p. 54-57 (in Russian).

[37] Dzhepo S.P., Skalsky A.S., Bugai D.A., Gudzenko V.V., Mogilny S.A., Proskura N.I. Testing-ground investigations of radionuclide migration in temporary area for radioactive waste localization "Ryzhy les" // Problems of Chernobyl exclusion zone, 1995, No 2, p. 77-84 (in Russian).

[38] Kopeikin V.A. Geochemical consequences of the Chernobyl accident. // Prob- 
lems of Chernobyl exclusion zone, 1995, No 2, p. 128-137 (in Russian).

[39] Borovoi A.A., Galkin B.Ya. et al. New formed products as the result of interaction between fuel and constructive materials at the 4 th block of Chornobyl Atomic Power Station. // Radiokhimiya, 1990, No 6, p. 103-113; 1991, No 4, p. 177-196 (in Russian).

[40] Felts A. Amorphous and glassy inorganic solids. Moscow, Mir, 1986, 556 p. (in Russian).

[41] Belousov Ju.A., Pushkarev M.V. On the calculation of viscosity for glassy silicate materials in wide assortments of content. // Phys. Chem. of Glass, 1994, vol. 20, No 3, p. 349-360 (in Russian).

[42] Siborg G.T., Cuts J.J. The chemistry of actinide elements. Moscow, Atomizdat, 1960, 541 p. (in Russian).

[43] Davydov Ju.P. State of radionuclides in solutions. Minsk, Nauka, Technika, 1978, 223 p. (in Russian).

[44] Analytical chemistry of elements. Uranium. Izdatelstvo Akademiji Nauk SSSR, 1962 (in Russian).

[45] Gekstra G, Katz D.D. In: Actinides. Ed. by Siborg G.T. Inostrannaja Literatura, Moscow-Leningrad, 1955 (in Russian).

[46] Brusilovskij S.A. Works of Institute for geology of ore deposites, mineralogy and geochemistry of Academy of Sciences of USSR. Izdatelstvo Akademiji Nauk SSSR, 1960, volume 42 (in Russian).

[47] Milukov M.S. et al. Analytical chemistry of plutonium. Nauka, Moscow, 1965 (in Russian).

[48] Belustin A.A. Concentration distribution for ions in surface layers of alkali silicate glasses processed with water solutions. // Phys. Chem. of Glass, 1981, vol. 7, No 1, p. 257-277 (in Russian).

[49] Bogolyubov N.N. Problems of dynamic theory in statistical physics. In: Bogolyubov N.N. Collected papers in three volumes. Vol. 2. Kiev, Naukova Dumka, 1970, 99 p. (in Russian).

[50] Blum L. Mean spherical model for asymmetric electrolytes I. Method of solution. // Mol. Phys., 1975, vol. 30, No 5, p. 1529-1535.

[51] Kuryliak I.J., Tokarchuk M.V. Statistical theory of electrolyte solutions transport through membrane structures. // Ukr. Fiz. Zhurn., 1991, vol. 36, No 8, p. 1179-1185 (in Ukrainian).

[52] Tokarchuk M.V., Omelyan I.P., Zhelem R.I. On the statistical theory of electrolyte solutions transport through membrane structures. Diffusion coefficients. // Cond. Mat. Phys., 1993, No 2, p. 94-102 (in Ukrainian).

[53] Pikaev A.K. Impulse radiolysis of water and aqueous solutions. Nauka, Moscow, 1965 (in Russian).

[54] Shubin V.N., Kabakchi S.A. Theory and methods of water radiation chemistry. Nauka, Moscow, 1969 (in Russian).

[55] Pikaev A.K., Kabakchi S.A., Makarov I.E. Hightemperature radiolysis of water and aqueous solutions. Energoatomizdat, Moscow, 1988 (in Russian).

[56] Li D. Action of irradiation on natural cels. Atomizdat, Moscow, 1963 (in Russian).

[57] Platzmann R.L. Basic mechanisms in radiobiology. U.S. Nat. Acad. Sci. Pub., 1953, No 305.

[58] Biakov B.M., Nichiporov F.G. Water radiolysios in nuclear reactors. Moscow, Energoatomizdat, 1990 (in Russian).

[59] Keizer J., Peacock-Lopez E. Energy transport effects on rapid bimolecular chemical reactions. // Physica, 1987, vol. 147, p. 61-76.

[60] Kaizer J. Statistical theormodynamics of nonequilibrium processes. Springer Verlag, Berlin, 1987.

[61] Hart E.J., Anbar M. The hydrated electron. New York, Wiley-Interscience, 1969.

[62] Klimontovich Yu.L., Wilhelmsson H., Yakimenko I.P., Zagorodny A.G. Sta- 
tistical theory of plasma-molecular systems. // Phys. Rep., 1989, vol. 175, No 5\&6, p. 263-401.

[63] Yukhnovskii I.R., Kuryliak I.J. Electrolytes. Kiev, Naukova Dumka, 1988 (in Russian).

[64] Yukhnovskii I.R., Holovko M.F. Statistical theory of classical equilibrium systems. Kiev, Naukova Dumka, 1980, 372 p. (in Russian).

[65] Kobryn A.E., Omelyan I.P., Tokarchuk M.V. Enscog-Landau kinetic equation for a two-component dense plasma. The solution, transport coefficients. / Preprint ICMP-93-19U, Lviv 1993, 40 p (in Ukrainian).

[66] A.E.Kobryn, I.P.Omelyan. Enskog-Landau kinetic equation for two-component dense plasma. The solution, transport coefficients. In: Abstracts and contributed papers of International Conference "Physics in Ukraine", Kiev, 1994, p. 135-138.

[67] Kobryn A.E., Omelyan I.P., Tokarchuk M.V. Normal solution and transport coefficients to the Enskog-Landau kinetic equation for a two-component system of charged hard spheres using the Chapman-Enscog method. Numerical calculation of transport coefficients for mixtures Ar-Kr, Ar-Xe, Kr-Xe. / Preprint ICMP-96-21U, Lviv 1996, 53 p. (in Ukrainian).

[68] Kobryn A.E., Omelyan I.P., Tokarchuk M.V. Normal solution and transport coefficients to the Enskog-Landau kinetic equation for a two-component system of charged hard spheres using the Chapman-Enscog method. Numerical calculation of transport coefficients for mixtures Ar-Kr, Ar-Xe, Kr-Xe. // Submitted to Physica A.

[69] Lebowitz J.L. Exact solution of generalized Percus-Yevick equation for a mixture of hard spheres. // Phys. Rev., 1964, vol. 133, No 4A, p. 895-889.

[70] Blum L., Høye J.S. Mean spherical model for asymetric electrolytes II. Thermodynamic properties and pair correlation function. // J. Phys. Chem., 1977, vol. 81, No 3, p. 1311-1316.

[71] J.H.Ferziger, H.G.Kaper, Mathematical theory of transport processes in gases, (North-Holland, Amsterdam, 1972).

\title{
ВИВЧЕННЯ НЕРІВНОВАЖНИХ ФІЗИКО-ХІМІЧНИХ ПРОЦЕСІВ У СИСТЕМІ "ПАЛИВОМІСНІ МАСИ - ВОДНІ РОЗЧИНИ РАДІОАКТИВНИХ ЕЛЕМЕНТІВ"
}

\author{
I.P.Юхновський, М.В.Токарчук, \\ В.В.Ігнатюк, О.С.Кобрин, І.П.Омелян, Р.І.ЖКелем, \\ Г.С.Дмитрів, О.Л.Іванків
}

Представлено основні форми перебування ядерного палива та пов'язані з ним головні фактори ядерної та екологічної небезпеки об'єкта “Укриття". Проаналізовано процеси взаємодії паливомісних мас з водою на основі експериментальних даних. Запропоновано статистичну модель опису взаємодії склоподібних паливомісних мас з водними розчинами радіоактивних елементів. Розраховані парні структурні функції розподілу іонів $\mathrm{UO}_{2}^{2+}, \mathrm{Cs}^{+}, \mathrm{Sr}^{2+}$ у водних розчинах. Проаналізовано хімічні реакції комплексоутворень за участю $\mathrm{UO}_{2}^{2+}, \mathrm{PuO}_{2}^{2+}$, а також реакції процесів радіолізу у водних розчинах радіоактивних елементів. Отримані неоднорідні рівняння для опису дифузії іонів $\mathrm{UO}_{2}^{2+}, \mathrm{Cs}^{+}, \mathrm{Sr}^{2+}$ із склоподібних паливомісних мас у водні розчини та рівняння хімічної кінетики процесів радіолізу. Проведено розрахунки коефіцієнтів взаємної дифузії та зсувної в'язкості іонів $\mathrm{UO}_{2}^{2+}, \mathrm{PuO}_{2}^{2+}, \mathrm{Cs}^{+}, \mathrm{Sr}^{2+}$ у водних розчинах, що є характерними для об'єкту “Укриття”. 